Article

\title{
Effect of Temperature, Pressure, Feed Particle Size, and Feed Particle Density on Structural Characteristics and Reactivity of Chars Generated during Gasification of Pittsburgh No.8 Coal in a High-Pressure, High-Temperature Flow Reactor
}

\author{
Vijayaragavan Krishnamoorthy and Sarma V. Pisupati *D \\ John and Willie Leone Family Department of Energy and Mineral Engineering and The EMS Energy Institute, \\ 110 Hosler Building, The Pennsylvania State University, University Park, PA 16802, USA; vijay.nit@gmail.com \\ * Correspondence: sxp17@psu.edu
}

Received: 14 November 2019; Accepted: 7 December 2019; Published: 14 December 2019

check for updates

\begin{abstract}
The gasification behavior of coal under high-temperature and high-pressure conditions is important from the perspective of designing and optimizing high efficiency gasifiers and troubleshooting existing gasifiers. The effect of feed particle size, density, temperature, and pressure on char porous structure, morphology, reflectance, and reactivity under conditions relevant to entrained-flow gasification was investigated. The chars were generated over a range of temperatures $\left(1100,1300\right.$, and $1400^{\circ} \mathrm{C}$ at 11.3 bar for the $-150+106 \mu \mathrm{m}$ fraction), pressures $(3.4,6.2,11.3,15.5$, and $21.7 \mathrm{bar}$ at $1300{ }^{\circ} \mathrm{C}$ for the $-150+106 \mu \mathrm{m}$ fraction), for various size fractions $(-106+75,-150$ $+106,-212+150,-420+212 \mu \mathrm{m}$ at $1300{ }^{\circ} \mathrm{C}$ and $\left.11.3 \mathrm{bar}\right)$, and density fractions $(<1.3,1.3-1.6$, $>1.6 \mathrm{~g} / \mathrm{cc}$ for the $-106+75 \mu \mathrm{m}$ at $1300{ }^{\circ} \mathrm{C}$ and 11.3 bar) of Pittsburgh No.8 bituminous coal using a high-pressure, high-temperature flow reactor (HPHTFR) in a equimolar mixture of $\mathrm{CO}_{2}$ and $\mathrm{N}_{2}$. Chars were characterized for conversion, morphology, thermal swelling ratio, and reactivity using ash tracer technique, oil immersion microscopy, tap density technique, and a thermogravimetric analyzer, respectively, and the results were statistically analyzed to determine for effects by feed particle density, feed particle size, temperature, and pressure. The results showed that the conversion was most affected by temperature, followed by feed particle size, pressure, and feed particle density. In the case of structural characteristics (i.e., thermal swelling ratio and group-I char concentration), feed particle density affected group-I concentration, while both feed particle size and feed particle density affected thermal swelling ratio. Variation in vitrinite content and fragmentation affected the thermal swelling ratio and group-I char concentration. In the case of intrinsic reactivity, particle density showed the largest effect, followed by temperature, particle size, and pressure. An increase in reflectance and temperature was found to inversely affect intrinsic reactivity.
\end{abstract}

Keywords: gasification; high pressure; reactivity; morphology

\section{Introduction}

The gasification process is one of the ways to utilize coal efficiently in a carbon-constrained world. However, there are some challenges associated with this technology [1,2]. One of the challenges is the poor understanding of the behavior of coal under high temperatures and high pressures. The gasification behavior of coal under high-temperature and high-pressure conditions is not well understood due to difficulty in designing and operating a reliable lab-scale reactor at high pressures 
and temperatures. This understanding is important from the perspective of designing and optimizing high efficiency gasifiers and troubleshooting existing gasifiers.

Gasification of char in entrained-flow gasifiers occurs in a pore diffusion control regime where the reaction is affected by both the intrinsic rate and the diffusion of reactants into the char pore structure [3]. The extent of diffusion of reactants into char is dependent on char pore structure and char morphology. Previous studies by Roberts et al. and Hodge et al. showed that the knowledge of char pore structure and morphology are important in arriving at kinetics of char in a pore diffusion controlled regime $[3,4]$. Therefore, to have similar morphology as chars from entrained flow gasifiers, chars must be generated under similar conditions.

Several high-pressure studies relevant to entrained flow gasifier have been conducted in the past that reported the pressure effects on structural characteristics (surface area and morphology) or reactivity, and sometimes both. Lee et al. measured structural characteristics and reactivity of chars generated in a high-pressure entrained-flow reactor over a pressure range of 1-38 bar, and at $1189^{\circ} \mathrm{C}[5,6]$. While the study was comprehensive in terms of measuring structural characteristics and reactivity, it was limited to one particle size. Kajitani et al. measured the rate of char reacting with $\mathrm{CO}_{2}$ for several different coal chars over the temperature range $1100-1500{ }^{\circ} \mathrm{C}$, the pressure range $2-20$ bar, and with $0.5-7$ bar $\mathrm{CO}_{2}$ partial pressure $[7,8]$. This work showed that the gasification rate occurs in pore diffusion control regime based on discontinuities in Arrhenius plots. The author provided no structural features of char. Ahn et al. also used a pressurized drop tube furnace to measure the char- $\mathrm{CO}_{2}$ reaction rate over the temperature range $900-1400{ }^{\circ} \mathrm{C}$, total pressures of $5-15$ bar, and $\mathrm{CO}_{2}$ partial pressures of 1-5 bar for a single coal [9]. The authors provided no detailed analysis of char properties such as char morphology. Benfell et al. measured the effect of petrography on morphology of chars generated from four Australian coals in a pressurized drop tube reactor over a pressure range of $5-15$ bar at $1300{ }^{\circ} \mathrm{C}$ [10]. While the study looked at various coals, the study was limited to one particle size fraction. Our previous studies measuring the role of pyrolysis gas, and reactor pressure over a range of $3-22$ bar at $1300{ }^{\circ} \mathrm{C}$, on intrinsic reactivity of chars from Pittsburgh no. 8 coal were also restricted to one particle size [11,12]. Other studies that looked at the effect of pressure on structural characteristics and/or reactivity also limited to one particle size fraction [13-15].

It is important to recognize that the particle size distribution of the feed to slurry gasifiers covers a wide range [16]. Feed particle size is known to affect thermal swelling ratio. Besides particle size, heterogeneity of coal macerals, composition, and concentration of inorganic matter can all affect char morphology $[16,17]$. The char morphology in turn can affect char kinetics and ash formation. Assuming pore structure, morphology, and kinetics to be uniform for the entire range of coal particle sizes can lead to inaccuracies of the kinetic model. Critical examination of the literature revealed that not a single comprehensive investigation was conducted to determine the effects of particle size and feed particle density on char morphology, pore structure, structural ordering, and the consequent effect on reactivity for chars generated at high pressures and temperatures relevant to that of entrained-flow gasification. This investigation focuses on the effects of feed particle size distributions, density fractions, operating temperature, and pressure on structural properties and reactivity of chars generated during high pressure gasification. This understanding is important in developing a robust kinetic model.

The main goal of this investigation is to determine the effects of pressure, temperature, particle size, and feed particle density on conversion, structural characteristics, and reactivity of the chars generated at elevated pressures. Pressure, temperature, feed particle size, and feed particle density all affect structural characteristics of the char, which in turn affect intrinsic reactivity. Therefore, it is imperative that the chars be generated under conditions similar to those of the chars generated in an entrained-flow gasifier. Additionally, the impact of various structural features on reactivity can give a broad understanding of the gasification behavior of coal under elevated pressures.

The specific research objectives of the investigation are 
1. To determine the effects of temperature, pressure, particle size, and inorganic matter on the structural features and the reactivity of the chars generated from a high-pressure, high-temperature laminar flow reactor.

2. Rank the effects of each of the parameters (i.e., pressure, temperature, feed particle size, feed particle density) on conversion, morphology, thermal swelling ratio, and intrinsic reactivity.

\section{Experimental}

\subsection{Coal Feed Characteristics}

Bituminous coals are the preferred feedstock for entrained-flow gasifiers [2]. Therefore, a widely used bituminous coal, Pittsburgh No. 8 seam coal, was used in this study. The coal was ground dry in a pilot scale rod mill to obtain a particle size distribution (PSD) very similar to the PSD of a coal fed into a commercial pressurized slurry fed entrained-flow gasifier. A representative sample of the ground coal was sieved to obtain four particle size fractions: $-106+75,-150+106,-212+150,-420+212 \mu \mathrm{m}$, to study the impact of particle size fractions on char characteristics and reactivity. These particle sizes were chosen as they together constitute $\sim 60 \%$ of the feed to a commercial entrained-flow gasifier [16]. Among these particle sizes, $-150+106 \mu \mathrm{m}$ was used to study the impact of pressure and temperature.

Another objective of the study was to investigate the effect of feed particle density on char reactivity. To obtain coal fractions of varying feed particle density, the whole quantity of coal of one particle size $(-106+75 \mu \mathrm{m})$ was further separated into three density fractions (SG) $(<1.3,1.3-1.6$, and $>1.6 \mathrm{~g} / \mathrm{cc}$ ) by the float-sink method described elsewhere [18], using mixtures of liquids of different densities (toluene/perchloroethylene). The methodology employed in this investigation is shown in Figure 1. Proximate analysis of the different coal density fractions showed that the $<1.3 \mathrm{~g} / \mathrm{cc}$ fraction had the lowest ash yield (3.3 wt.\%), the 1.3-1.6 g/cc fraction with intermediate ash yield (7.5 wt.\%), and the $>1.6 \mathrm{~g} / \mathrm{cc}$ fraction with the highest ash yield (65.3 wt.\%). 


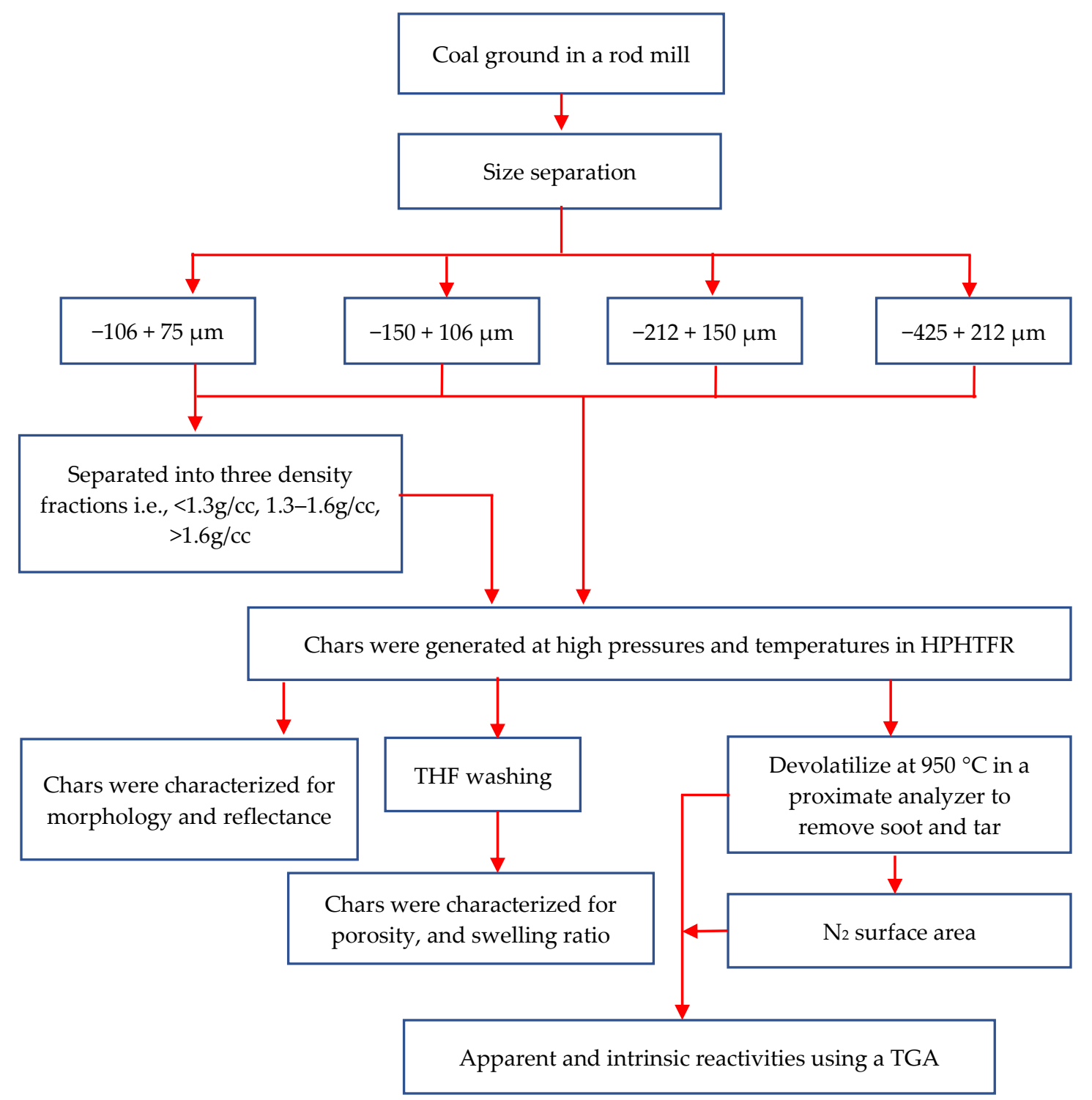

Figure 1. Research methodology used in the study.

Similarly, the volatile yield also decreased with density fraction. While no such clear trend of ash yield was observed for different particle size fractions, the coarser particle size fractions $(-212+150$ and $-420+212 \mu \mathrm{m})$ showed slightly higher ash yield compared to finer particle size fractions $(-106$ +75 and $-150+106 \mu \mathrm{m})$. The lower ash yield for finer size fractions is possibly due to liberation of ash during grinding. The proximate and ultimate analyses of all the samples used in this study are provided in Table 1. 
Table 1. Compositional analysis of feed samples.

\begin{tabular}{ccccccccc}
\hline \multirow{2}{*}{ Particle Size Fraction $(\boldsymbol{\mu m})$} & \multicolumn{3}{c}{ Proximate Analysis $(\mathbf{w t .} \%, \mathbf{d b})$} & \multicolumn{3}{c}{ Ultimate Analysis $(\mathbf{w t} . \%, \mathbf{d b})$} \\
\cline { 2 - 8 } & $\mathbf{V M}$ & FC & Ash & $\mathbf{C}$ & $\mathbf{H}$ & $\mathbf{N}$ & $\mathbf{S}$ & $\mathbf{O}$ \\
\hline$-425+212$ & 40.4 & 50.5 & 9.1 & 81.2 & 5.2 & 1.3 & 2.2 & 1.0 \\
$-212+150$ & 36.6 & 52.6 & 10.8 & 79.9 & 5.0 & 1.1 & 2.1 & 1.1 \\
$-150+106$ & 38.0 & 54.7 & 7.3 & 82.2 & 5.4 & 1.6 & 1.5 & 2.0 \\
$-106+75$ & 38.2 & 53.5 & 8.3 & 82.0 & 5.1 & 1.5 & 1.6 & 1.5 \\
$<1.3 \mathrm{~g} / \mathrm{cc}$ fraction of $-106+75$ & 38.1 & 58.6 & 3.3 & 85.6 & 5.6 & 1.5 & 1.2 & 2.8 \\
$1.3-1.6$ g/cc fraction of $-106+75$ & 35.8 & 56.7 & 7.5 & 82.1 & 5.0 & 1.4 & 1.7 & 2.3 \\
$>1.6$ g/cc fraction of $-106+75$ & 16.2 & 18.5 & 65.3 & 23.9 & 1.6 & 0.4 & 8.4 & 0.4 \\
\hline
\end{tabular}

db: dry basis; VM: volatile matter; FC: Fixed carbon.

\subsection{High-Pressure, High-Temperature Flow Reactor}

All the experiments were conducted in an electrically heated high-pressure, high-temperature flow reactor (HPHTFR) operated under laminar flow conditions. The reactor is designed to operate at a maximum of $1650^{\circ} \mathrm{C}$ and 30 bar pressure. The reactor consists of consists of a high alumina ceramic (reaction) tube $(65 \mathrm{~mm}$ i.d $\times 700 \mathrm{~mm}$ long) with a mullite flow straightener (honeycomb) placed at the top surrounded by six super Kanthal heating elements, all encased in a refractory-casted, lined carbon steel pressure vessel. The concentric section between the refractory wall and the outer surface of the reaction tube was used to preheat secondary gas. Inert gas was used as the primary gas to transport particles from the feeder to the reaction zone. The gases were supplied by gas cylinders, and the flow rates were controlled by calibrated mass flow controllers. The reactor temperature was continuously monitored by a thermocouple placed close to the outer surface of the ceramic tube around the mid-section. Once the desired temperature was achieved, the reactor was purged with the reaction gas for a few minutes. After which, the reactor pressure was increased using a back-pressure regulator. The gas was allowed to flow for about 10-15 min at the desired pressure until the gas composition exiting the reactor, monitored using a calibrated micro gas chromatograph, reached the inlet gas composition. The schematic of the reactor is shown in Figure 2. 


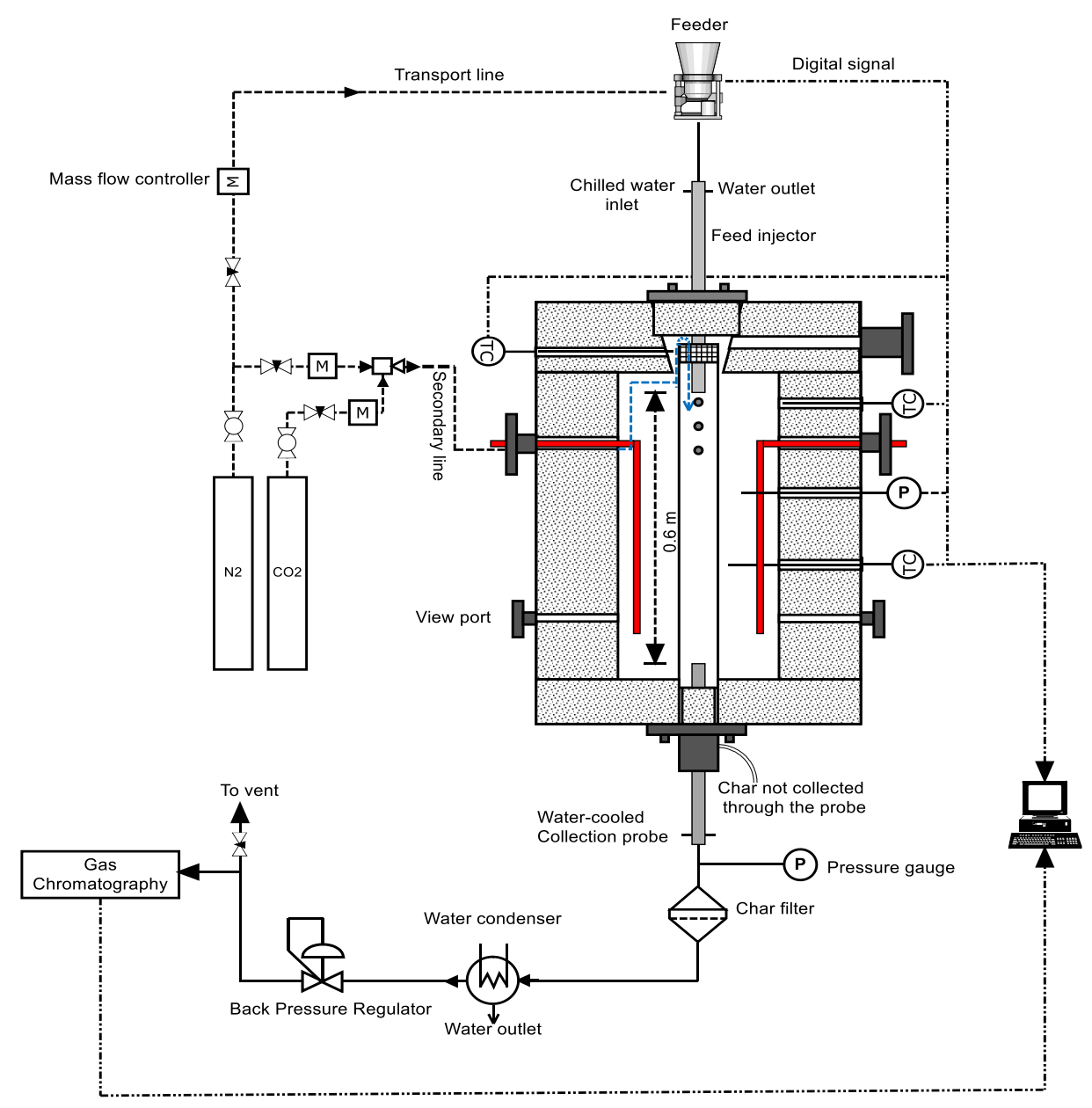

Figure 2. Schematic of the high-pressure, high-temperature flow reactor.

For this study, a sample of about $30-45 \mathrm{~g}$ was dry fed into the reactor at a stable feed rate of $3.00 \pm 0.02 \mathrm{~g} / \mathrm{min}$ for all particle sizes. Each sample was entrained into the reactor through a water-cooled feed injector using $\mathrm{N}_{2}$ as the primary gas. Primary gas constitutes about $10 \%-15 \%$ of the total flow rate through the reactor. The bulk of the flow rate $(85 \%-90 \%)$ through the reactor comes from secondary gas, which was composed of $\mathrm{CO}_{2}$ and $\mathrm{N}_{2}$. The gas flow rates used for these experiments ranged between 33 standard liters per minute (slpm) at 3.4 bar to $150 \mathrm{slpm}$ at 21.7 bar. Oxygen was not used in any of the experiments as the study was aimed at simulating the second stage of the slurry-fed gasifier without steam. The gas composition in the reactor was always maintained at $\approx 50$ vol. \% $\mathrm{CO}_{2}$, with the rest being $\mathrm{N}_{2}$. The gas composition was constantly monitored using the micro gas chromatograph (micro-GC). The particle residence time was determined by solving the force balance equation for particle velocity. The force balance is given by:

$$
m_{p} a=\frac{4}{3} \pi \mathrm{r}^{3} \rho_{p} \frac{d V_{p}}{d t}=\frac{4}{3} \pi \mathrm{r}^{3}\left(\rho_{g}-\rho_{p}\right) \mathrm{g}+\frac{1}{2} \pi \mathrm{r}^{2} \rho_{g}\left(\mathrm{~V}_{\mathrm{g}}-\mathrm{V}_{\mathrm{p}}\right)^{2} \mathrm{C}_{\mathrm{D}}
$$

where " $a$ " is acceleration and is a derivation of particle velocity $\left(V_{p}\right)$ with respect to time. The mass of the particle is expressed as the product of volume of the particle and the particle density $\left(\rho_{\mathrm{p}}\right) . \rho_{\mathrm{g}}$ is the density of the gas. $V_{g}$ is the velocity of gas. The drag coefficient $\left(C_{D}\right)$ in Equation (1) is given by:

$$
C_{D}=\left(\sqrt{\frac{24}{R e}}+0.5407\right)^{2} .
$$


The drag coefficient is valid for spheres with Reynolds number $(\operatorname{Re})<6000$. The residence time, taking particle density into account, was calculated to be between 2.0 and $2.8 \mathrm{~s}$.

Upon injection of the sample into the reactor, the particles react with the reaction gas as they pass through the $0.60 \mathrm{~m}$ reaction zone to form char-ash particles. The char-ash particles collected through the water-cooled probe were captured by a series of filters with the last filter having a mesh opening of $1 \mu \mathrm{m}$. The resulting product gas exited the filter at room temperature and was further cooled in a heat exchanger to remove any remaining moisture before analyzed for components via micro-GC. The char sample collected in the filter could be contaminated with tar and soot. All the char samples except the char from $>1.6 \mathrm{~g} / \mathrm{cc}$ fraction were washed with tetrahydrofuran (THF) to remove tar and soot deposited on the char surface. The removal of tar/soot from char was done by washing the sample with tetrahydrofuran (THF). THF is known to provide greater extractability of coal tar without altering the char characteristics [19]. The procedure for washing the samples with THF is described elsewhere [20]. The THF washed samples were analyzed for ash, surface area, swelling ratio, and reactivity as described in the following section.

\subsection{Char Analysis}

\subsubsection{Proximate Analysis}

Proximate analysis of THF washed chars was carried out in a LECO MAC 400 analyzer. Approximately $0.15 \mathrm{~g}$ of sample was crushed to pass through a $150 \mu \mathrm{m}$ screen before analysis. The analysis was duplicated to obtain average volatile matter, ash, and fixed carbon. Total conversion was calculated using ash as the tie component, assuming inorganic components did not volatilize during the gasification process and all ash particles were collected from the reactor.

\subsubsection{Surface Area Analysis and Pore Size Distribution}

Total surface area and pore size distribution of THF washed chars were determined using $\mathrm{N}_{2}$ adsorption-desorption isotherms at $77 \mathrm{~K}$. The isotherms were analyzed using the Brunauer-Emmett-Teller (BET) equation to calculate total surface area, and Barrett-Joyner-Halenda $(\mathrm{BJH})$ analysis to calculate pore size distribution.

\subsubsection{Thermal Swelling Ratio Measurements}

The tap density technique, as described by Fletcher [21], was used to find the ratio of apparent density of the char sample to that of the parent coal sample. A known amount of the sample was filled in a graduated cylinder and tapped until coal/char settles and the mass per unit volume was determined. The density ratio was determined assuming the packing factor for coal and the char to be same. From the extent of mass release and apparent density ratio, swelling factor was calculated by [21]:

$$
\frac{m}{m_{0}}=\frac{\rho}{\rho_{o}} \times\left(\frac{d}{d_{0}}\right)^{3},
$$

where, $d / d_{0}$ represents swelling ratio. The subscript " $o$ " refers to parent coal and without it refers to char. The mass ratio $m / m_{o}$ in the equation is expressed on a dry basis. The density ratio $\rho / \rho_{o}$ refers to the ratio of apparent densities, where apparent density is defined as the mass of a particle divided by the total volume enclosed by the outer surface of the particle (assumed to be spherical). 


\subsubsection{Morphology and Petrographic Analysis}

Morphology and petrographic analysis were performed on the char samples prior to washing the char with THF. The analysis was performed on a polished cross section of the sample that was prepared by mixing the char particles with cold setting epoxy. Point count analysis was performed using the Zeiss Universal research microscope at $625 \times$ magnification with polarized light. While there are different ways of classifying observed char structures [22-24], the classification system proposed by Bailey et al. [24] was employed in this study. Morphology of the chars, and ash were manually quantified using point-count readings as described in Gilfillan et al. [25]. A minimum of 85 morphological points was identified. The char types identified include tenuisphere, tenuinetwork, crassisphere, crassinetwork, solids, mixed porous, mixed dense, fusinoid, inertinoid, and fragments. These types are categorized into four groups-group-I ( $>70 \%$ porosity and $<5 \mu \mathrm{m})$, group-II $(40 \%-70 \%$ porosity, $>5 \mu \mathrm{m})$, group-III ( $<40 \%$ porosity and variable thickness), and fragments. The summary of char classification system employed in this study is shown in Table 2.

Table 2. Summary of char classification system.

\begin{tabular}{ccccc}
\hline Char Type & Group-I & Group-II & Group-III & Fragment \\
\hline Porosity and Wall & $>70 \%$ porosity and & $\begin{array}{c}40 \%-70 \% \text { porosity } \\
\text { Thickness }\end{array}$ & $<40 \%$ porosity and & No porosity and \\
Morphology & $\begin{array}{c}\text { Tenuisphere and } \\
\text { tenuinetwork }\end{array}$ & $\begin{array}{c}\text { Crassisphere, } \\
\text { crassinetwork, and } \\
\text { mixed porous }\end{array}$ & $\begin{array}{c}\text { Mixed dense, } \\
\text { fusinoid, inertinoid, } \\
\text { and solids }\end{array}$ & $\begin{array}{c}\text { Fragment } \\
\end{array}$ \\
\hline
\end{tabular}

The uncertainty in the categorization was determined by analyzing the two longitudinal sections of $<1.3 \mathrm{~g} / \mathrm{cc}$ of $-106+75 \mu \mathrm{m}$ char sample generated at $1300{ }^{\circ} \mathrm{C}$ two times each. The overall standard deviation for group-I char, group-II type, group-III type, and fragments was $6.8 \%, 3.5 \%, 2.7 \%$, and $4.4 \%$, respectively. The variation in char morphology in most cases is primarily due to group-I char and fragments. Although care was taken while handling the chars, some fragmentation was a result of handling the fragile group-I char particles.

Random reflectance of samples was determined using reflectance microscopy. A mean random reflectance was obtained on a vitrinite-derived char cross section over the polished surface. The mean random reflectance was reported based on an average of a minimum 20 readings. The overall variation in the readings was quantified assuming $\mathrm{t}$-distribution and reflectance was found to vary between $0.19 \%$ and $0.45 \%$.

\subsubsection{High Resolution Transmission Electron Microscopy (HRTEM) Analysis}

The samples were prepared by crushing under ethanol in a mortar. A suspension of the crushed particles was then deposited on a carbon film. The high-resolution transmission electron microscope images (Structural resolution limit $=0.12 \mathrm{~nm}$ ) were obtained using a Talos F200X operated at $200 \mathrm{kV}$ with EDS detector for determining elemental composition.

\subsubsection{Image Analysis}

Char samples were prepared by mounting a small amount of sample on a $10 \mathrm{~mm}$ diameter stub. The external morphology of chars was obtained using FEI Quanta 200 scanning electron microscope operated in a backscattered mode at $20 \mathrm{kV}$ in a high vacuum with a spot size of 7 .

\subsubsection{Char Reactivity}

Char reactivity was measured using a Rubotherm thermogravimetric analyzer at $400{ }^{\circ} \mathrm{C}$ and 1 bar. Chars were found to contain a lot of volatile matter and it varied for different chars. To remove 
the effect of residual volatiles on reactivity, char samples were further devolatilized in a proximate analyzer at $950{ }^{\circ} \mathrm{C}$ and 1.01 bar for $7 \mathrm{~min}$.

To determine the reactivity, a small amount of the devolatilized char sample $(\approx 10 \mathrm{mg})$ was heated to $400^{\circ} \mathrm{C}$ at a heating rate of $10^{\circ} \mathrm{C} / \mathrm{min}$. A stream of $\operatorname{Ar}(100 \mathrm{~mL} / \mathrm{min})$ was used to sweep the char sample during the heat-up period. After thermal equilibration at the desired temperature for few minutes, the isothermal step was initiated by switching Ar with $\mathrm{O}_{2}$ at the same flow rate. The apparent reactivity was determined on devolatilized chars at $400{ }^{\circ} \mathrm{C}$ in $\mathrm{O}_{2}$ atmosphere at $5 \%$ conversion. The reason that went into choosing $5 \%$ conversion for reactivity was to allow some time for $\mathrm{O}_{2}$ concentration to equilibrate in the TGA after transitioning from Ar atmosphere.

Apparent reactivity was calculated as the rate of weight loss with respect to the instantaneous char mass by:

$$
\mathrm{R}_{\mathrm{a}}=\frac{1}{\mathrm{~m}_{\mathrm{i}}} \times \frac{\mathrm{dm}}{\mathrm{dt}} \frac{\mathrm{g}}{\mathrm{g} \cdot \mathrm{min}} .
$$

Apparent reactivity $\left(\mathrm{R}_{\mathrm{a}}\right)$ is a combination of effects of char surface activity and surface area. By normalizing the apparent reactivity with the $\mathrm{N}_{2}$ surface area (SA), intrinsic reactivity was determined by:

$$
\mathrm{R}_{\mathrm{i}}=\frac{\mathrm{R}_{\mathrm{s}}}{\mathrm{SA}} \frac{\mathrm{g}}{\mathrm{m}^{2} \cdot \min } .
$$

It is likely that chars devolatilized further in the proximate analyzer could have fragmented due to their fragile nature. The surface area was measured again on devolatilized chars and used for determining intrinsic reactivity. It was assumed that the surface area of the char at $5 \%$ conversion with $\mathrm{O}_{2}$ may not be different from the char fed into the TGA. The validity of the intrinsic reactivity at $400{ }^{\circ} \mathrm{C}$ was tested by determining the kinetics of $11.3 \mathrm{bar} / 1300^{\circ} \mathrm{C}$ char with $\mathrm{O}_{2}$ over the temperature range of $350-400{ }^{\circ} \mathrm{C}$ and 1 bar. The regression equation was found to be 0.99 . This confirms the reaction was free of mass transfer limitation at $400^{\circ} \mathrm{C}$.

It is likely that devolatilization of chars at $950^{\circ} \mathrm{C}$ can alter reactivity. To quantify the impact of devolatilization on the reactivity, the THF washed char and the devolatilized char generated from $-150+106 \mu \mathrm{m}$ at 3.4 bar pressure were compared for apparent and intrinsic reactivities obtained with $\mathrm{O}_{2}$ at $400{ }^{\circ} \mathrm{C} / 1.01$ bar. While the apparent reactivity of devolatilized char $\left(\mathrm{R}_{\mathrm{a}}=11.5 \times 10^{-3}\right.$ $\left.\min ^{-1}\right)$ was $118 \%$ times higher than THF washed char $\left(R_{a}=5.27 \times 10^{-3} \mathrm{~min}^{-1}\right)$, the intrinsic reactivity of the devolatilized char $\left(R_{i}=3.95 \times 10^{-5} \mathrm{~g} / \mathrm{m}^{2} \cdot \mathrm{min}^{-1}\right)$ was $20 \%$ lower than the THF washed char $\left(R_{\mathrm{i}}=4.84 \times 10^{-5} \mathrm{~g} / \mathrm{m}^{2} \cdot \mathrm{min}^{-1}\right)$. The difference was attributed to increased fragmentation leading to increased surface area of the devolatilized char (i.e., $109 \mathrm{~m}^{2} / \mathrm{g}$ for THF washed char to $291 \mathrm{~m}^{2} / \mathrm{g}$ for devolatilized char). This shows that the impact of devolatilization on intrinsic reactivity of chars is minimal.

\subsubsection{Uncertainty Analysis}

Variation in reactor temperature, reaction gas flow rates, and coal feed rate can all contribute to variation in coal conversion. Determining the effect of each of these individual parameters on coal conversion can be cumbersome and complex. While most of the experiments were run at least twice, uncertainty in conversion was calculated by generating chars from the particle size fraction of $-150+106 \mu \mathrm{m}$ at $1300{ }^{\circ} \mathrm{C}$ and $6.2 \mathrm{bar}$ by repeating four times. The average ash content of each of the THF washed char samples was determined based on the duplicates in the proximate analyzer. The uncertainty around the average conversion was determined using $\mathrm{t}$-distribution with $95 \%$ confidence interval. The standard error for conversion was calculated to be $8.2 \%$.

Similarly, the uncertainty in the average apparent reactivity with $95 \%$ confidence interval was determined by repeating the char sample obtained from $-150+106 \mu \mathrm{m}$ particle size fraction at $1300^{\circ} \mathrm{C}$ and 11.3 bar for $\mathrm{O}_{2}$ reactivity four times. The error was found to be $0.0009 \mathrm{~min}^{-1}$. 


\section{Results and Discussion}

\subsection{Effect of Reactor Pressure}

Effect of reactor pressure on carbon conversion for the $-150+106 \mu \mathrm{m}$ particle size fraction at $1300{ }^{\circ} \mathrm{C}$ is shown in Figure $3 \mathrm{~A}$. The average conversion varied between $\approx 43 \pm 8.2 \mathrm{wt}$. $\%$ at 3.4 bar and $\approx 59 \pm 8.2 \mathrm{wt}$.\% for 21.7 bar pressure. Lower conversion for chars generated at 3.4 and 6.2 bar pressures can be attributed to $20 \%$ lower particle residence time $(\approx 2.0 \mathrm{~s})$ as compared to chars generated at higher pressures $(\approx 2.5 \mathrm{~s}$ for chars generated at $11.3,15.5$, and 21.7 bar). Even though there is a difference in total conversion across the pressure range examined, the uncertainty of $8.2 \%$ around average conversion suggests that the pressure has no significant effect on conversion. It appears that at higher temperature, and in the presence of a reaction gas, the impact of pressure on conversion is limited. Zeng and Fletcher also showed that pressure has limited impact on conversion over a range of 2.5-15 bar [13]. It is also noteworthy that chars had about $\approx 20 \%$ of volatiles on dry ash free basis (see Table 3 ). While it is known that increase in pressure increases fluidity during initial stages of pyrolysis for a coal like Pittsburgh no.8 [26], higher residual volatile matter appears to be unusual for sample with $\approx 50 \%$ conversion. Duplicate runs with the same sample yielded a similar amount of volatiles confirming that this is not due to any experimental error. The unusual observation of higher residual volatiles could be due to higher temperature $\left(\geq 1100^{\circ} \mathrm{C}\right)$, higher pressure $(>1$ bar $)$, and lower residence time $(2.0-2.5 \mathrm{~s})$ in the reactor at which these chars were generated compared to minutes at atmospheric pressure and $950{ }^{\circ} \mathrm{C}$ used in American Society for Testing and Materials (ASTM) volatile matter determination. Higher pressure prevents the release of volatiles, and higher temperature increases the volatile generation both could have contributed to higher residual volatiles for the char generated from the HPHTFR.

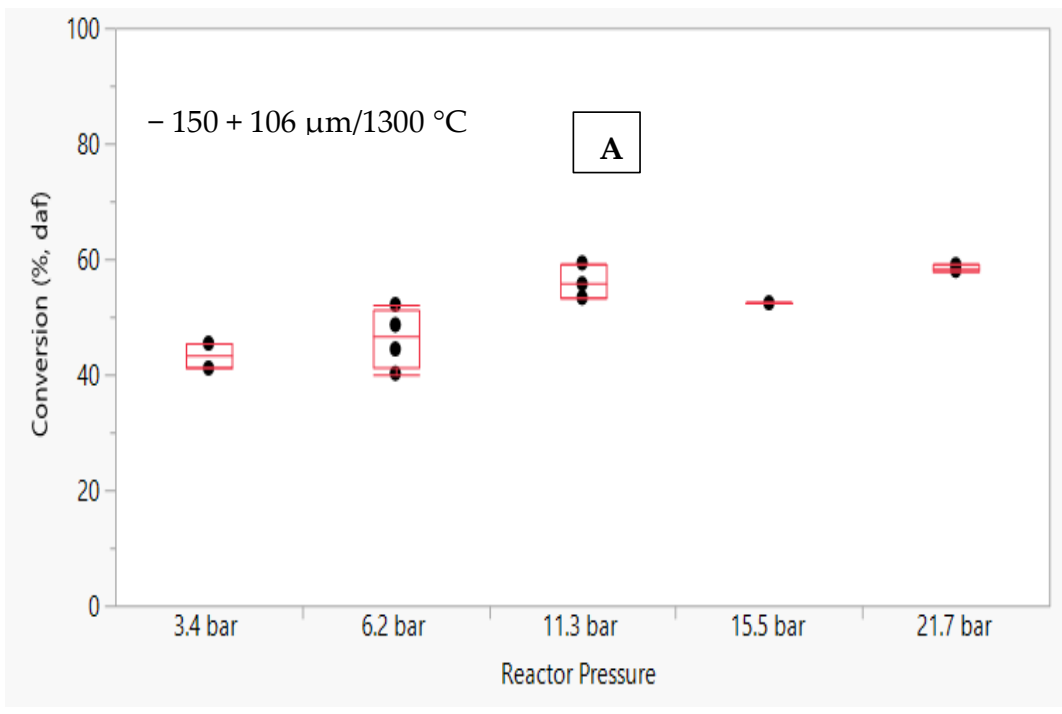

Figure 3. Cont. 


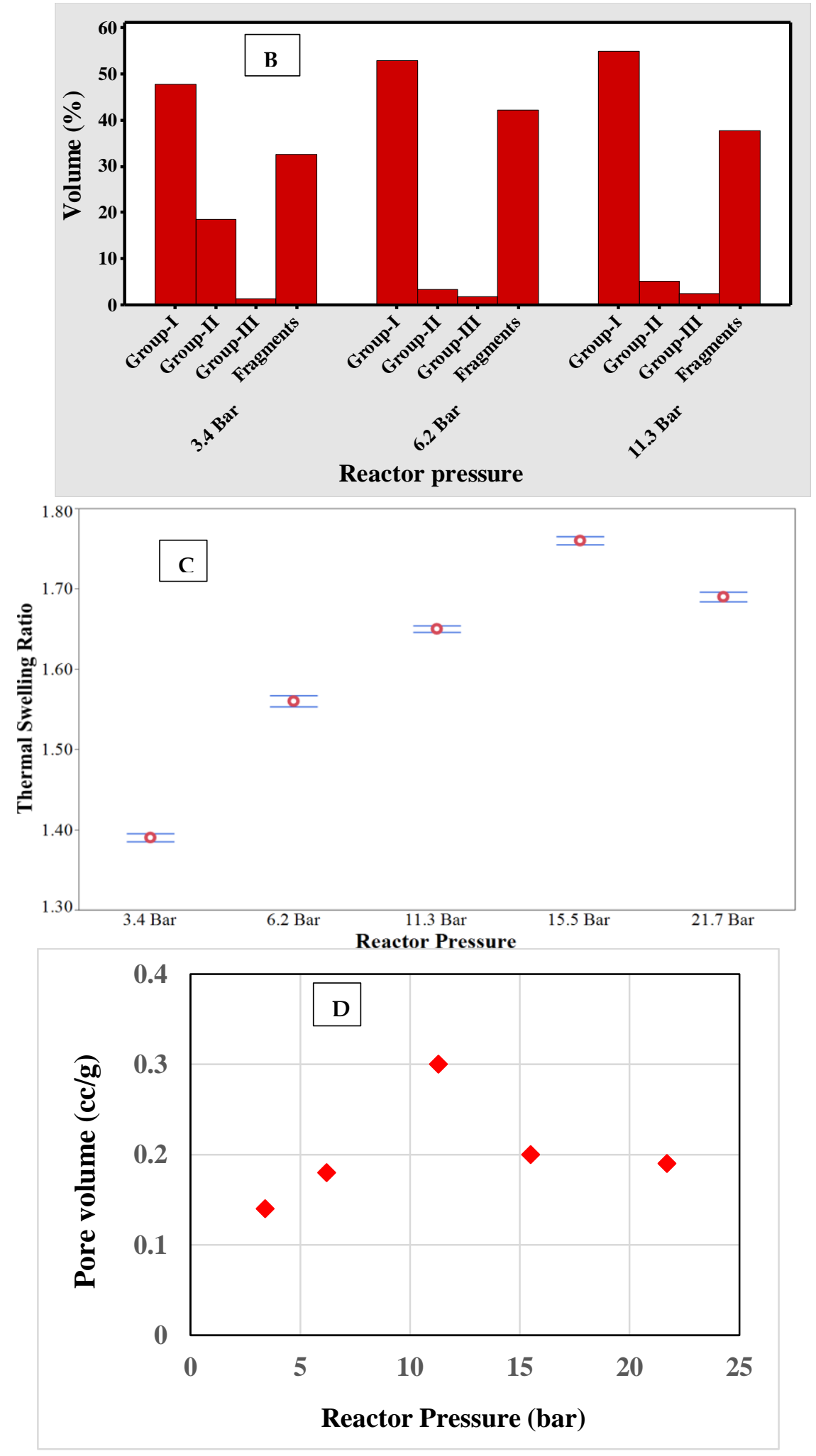

Figure 3. Cont. 


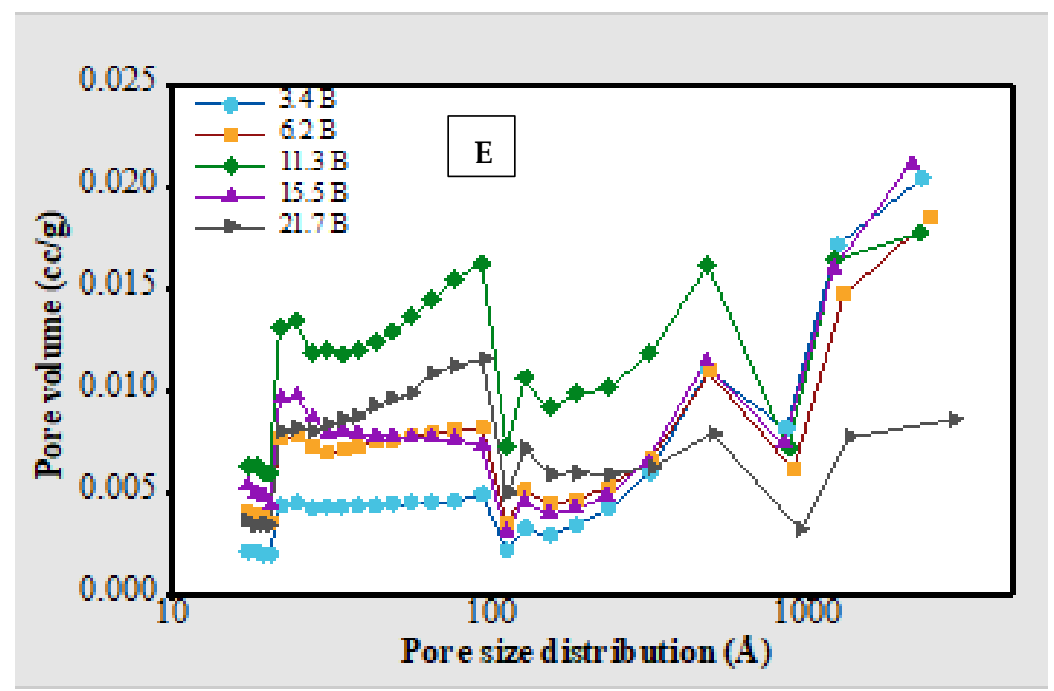

Figure 3. Effect of reactor pressure on (A) coal conversion (95\% CI: $\pm 8.2 \%$ ), (B) morphology, (C) thermal swelling ratio, (D) pore volume, (E) pore size distribution.

Table 3. Properties of char analyzed (after washing with tetrahydrofuran (THF)).

\begin{tabular}{|c|c|c|c|c|c|c|c|}
\hline \multirow{2}{*}{$\begin{array}{l}\text { Feed Particle } \\
\text { Size/Density }\end{array}$} & \multirow{2}{*}{$\begin{array}{c}\text { Experimental } \\
\text { Conditions }\end{array}$} & \multicolumn{3}{|c|}{ Proximate Analysis (wt.\%, db) } & \multirow{2}{*}{$\begin{array}{c}\text { Surface } \\
\text { Area } \\
\left(\mathrm{m}^{2} / \mathrm{g}\right)\end{array}$} & \multirow{2}{*}{$\begin{array}{c}\text { Pore } \\
\text { Volume } \\
\text { (cc/g) }\end{array}$} & \multirow[t]{2}{*}{$\mathbf{R}_{\mathrm{r}}^{*}(\%)$} \\
\hline & & VM & FC & Ash & & & \\
\hline \multicolumn{8}{|c|}{ Effect of Pressure } \\
\hline \multirow{5}{*}{$-150+106 \mu \mathrm{m}$} & $3.4 \mathrm{bar} / 1300^{\circ} \mathrm{C}$ & 17.8 & 70.0 & 12.2 & 109 & 0.14 & $7.20 \pm 0.19$ \\
\hline & $6.2 \mathrm{bar} / 1300^{\circ} \mathrm{C}$ & 19.2 & 68.1 & 12.7 & 232 & 0.18 & $7.32 \pm 0.22$ \\
\hline & $11.3 \mathrm{bar} / 1300^{\circ} \mathrm{C}$ & 19.6 & 64.7 & 15.7 & 332 & 0.30 & $8.03 \pm 0.45$ \\
\hline & $15.5 \mathrm{bar} / 1300^{\circ} \mathrm{C}$ & 19.1 & 66.7 & 14.2 & 289 & 0.20 & NA \\
\hline & $21.7 \mathrm{bar} / 1300^{\circ} \mathrm{C}$ & 18.2 & 65.9 & 15.9 & 170 & 0.19 & NA \\
\hline \multicolumn{8}{|c|}{ Effect of Temperature } \\
\hline \multirow{3}{*}{$-150+106 \mu \mathrm{m}$} & $1100^{\circ} \mathrm{C} / 11.3 \mathrm{bar}$ & 21.3 & 68.6 & 10.1 & 7 & 0.02 & $6.86 \pm 0.23$ \\
\hline & $1300^{\circ} \mathrm{C} / 11.3 \mathrm{bar}$ & 19.6 & 64.7 & 15.7 & 332 & 0.30 & $8.03 \pm 0.45$ \\
\hline & $1400^{\circ} \mathrm{C} / 11.3 \mathrm{bar}$ & 17.0 & 62.8 & 20.2 & 136 & 0.14 & $8.16 \pm 0.41$ \\
\hline \multicolumn{8}{|c|}{ Effect of Feed Particle Density } \\
\hline$<1.3 \mathrm{~g} / \mathrm{cc}^{\mathrm{a}}$ & & 24.8 & 66.5 & 8.7 & 327 & 0.25 & $8.05 \pm 0.42$ \\
\hline $1.3-1.6 \mathrm{~g} / \mathrm{cc}^{\mathrm{a}}$ & $1300^{\circ} \mathrm{C} / 11.3 \mathrm{bar}$ & 21.6 & 59.2 & 19.2 & 261 & 0.21 & $7.85 \pm 0.44$ \\
\hline$>1.6 \mathrm{~g} / \mathrm{cc}^{\mathrm{a}, *}$ & & 5.8 & 2.7 & 91.5 & 11 & 0.02 & ND \\
\hline \multicolumn{8}{|c|}{ Effect of Initial Particle Size Distribution } \\
\hline$-425+212 \mu \mathrm{m}$ & & 17.4 & 68.8 & 13.8 & 119 & 0.08 & $7.08 \pm 0.37$ \\
\hline$-212+150 \mu \mathrm{m}$ & & 20.0 & 62.3 & 17.7 & 196 & 0.12 & $7.17 \pm 0.31$ \\
\hline$-150+106 \mu \mathrm{m}$ & $1300^{\circ} \mathrm{C} / 11.3 \mathrm{bar}$ & 19.6 & 64.7 & 15.7 & 332 & 0.30 & $8.03 \pm 0.45$ \\
\hline$-106+75 \mu \mathrm{m}$ & & 21.4 & 58.0 & 20.6 & 333 & 0.30 & $7.98 \pm 0.36$ \\
\hline
\end{tabular}

$\mathrm{db}$ : dry basis, $\% \mathrm{Rr}=\%$ random reflectance, ${ }^{\mathrm{a}}-106+75 \mu \mathrm{m}$ feed particle size fraction was used, ${ }^{*}$ Analysis done before washing with THF.

If the hypothesis of pressure and temperature playing a dominant role on residual volatiles is true, chars from commercial gasifier with similar or longer residence time should also show significant residual volatile matter (on dry ash free basis). This hypothesis was supported by a char/slag sample collected from a particulate filter from a commercial gasifier that showed $>50 \%$ volatiles (on dry ash free basis) with respect to the feed [27]. Other commercial gasifier char samples analyzed in our laboratory also revealed a significant presence of volatiles ( $>40 \%$ of volatiles with respect to the feed) despite more than $5 \mathrm{~s}$ particle residence time. All these results from commercial gasifiers prove that residual volatile matter of $\approx 50 \%$ compared to feed in char after $2 \mathrm{~s}$ residence time is not an abnormal observation. 
Char morphology is an important parameter for modeling char- $\mathrm{CO}_{2}$ reactivity in an entrained-flow gasifier [4]. Highly porous group-I chars tend to show higher reactivity under a pore diffusion controlled regime due to a higher effectiveness factor compared to less porous group-III chars. From this perspective, effect of pressure on char morphology is important in kinetic model development. Figure 3B shows the morphology through groups of the chars generated at different pressures. The pressure has no statistically significant effect on group-I char formation as pressure was increased from 3.4 bar ( $48 \pm 6.8$ vol. $\%$ ) to 11.3 bar ( $55 \pm 6.8$ vol. $\%$ ). Correspondingly, group-II char formation decreased from $\approx 18 \pm 3.5$ vol. $\%$ at 3.4 bar to $\approx 5 \pm 3.5$ vol. $\%$ at 11.3 bar. The significant drop in group-II char concentration happened between 3.4 and 6.2 bar where the concentration of group-II char dropped to $\approx 3 \pm 3.5 \mathrm{vol} . \%$. Transformation of group-II char to group-I char can be attributed to increased fluidity with pressure. Increased fluidity of char at higher reactor pressure can be attributed to suppression of escape of tar precursors which otherwise would have evaporated at lower pressures [26]. The volatiles (including tars) trapped within the particle expand to increase the particle diameter thereby thinning the wall. This led to generation of hollow group-I char. Interestingly, a further increase in pressure to 11.3 bar did not change the concentration of group-I char significantly. The caking coals like that of Pittsburgh No.8 generate a lot of fluidity $[26,28]$ and quickly transform to balloon type cenospheres (i.e., group-I char) even at lower pressures $(<5$ bar), and further increase in pressure does not significantly alter the group-I char concentration.

Although group-I char concentration did not change much at elevated pressures, thermal swelling ratio increased from 1.39 to 1.76 even as pressure was increased from 3.4 to 15.5 bar. As the pressure was further increased to $21.7 \mathrm{bar}$, the thermal swelling ratio decreased to 1.69 . Figure $3 \mathrm{C}$ shows the effect of pressure on thermal swelling ratio. Earlier studies have indicated that the maximum swelling (both at low heating rate and high heating rate) for caking coals occurs in the 8-20 bar pressure range (external pressure) and then decreases with further increase in pressure [13,28-31]. Increase in thermal swelling ratio with pressure and the decline after that can be explained based on the mechanism proposed by Yu et al. [32]: During the devolatilization process, a considerable amount of volatiles are transported in as vapors and gases in the form of bubbles. Small bubbles are created during the initial stages of pyrolysis. At lower pressures, the bubbles merge to form larger bubbles, move to the exterior surface, and burst open. This occurs due to limited mass transfer resistance. As the external reactor pressure increases, the diffusion of volatiles out of the particle becomes slower due to lower pressure gradient. The volatiles trapped within the particles expand to increase the diameter thereby thinning the walls until a balance of forces is established with the exterior reactor pressure. The expansion with increase in pressure results in the generation of highly porous chars with increased thermal swelling ratio. Above a certain pressure, the external force becomes more than the internal pressure resulting in a reduction in swelling. Additionally, the volatile release through bubble transport is restricted and the blow holes are reduced resulting in a char structure with an early stage of bubble evolution (i.e., smaller bubbles). SEM micrographs, shown in Figure 4, confirm that the pore evolution is in the earlier stages for the char generated for higher pressure char as compared to a lower pressure char. 


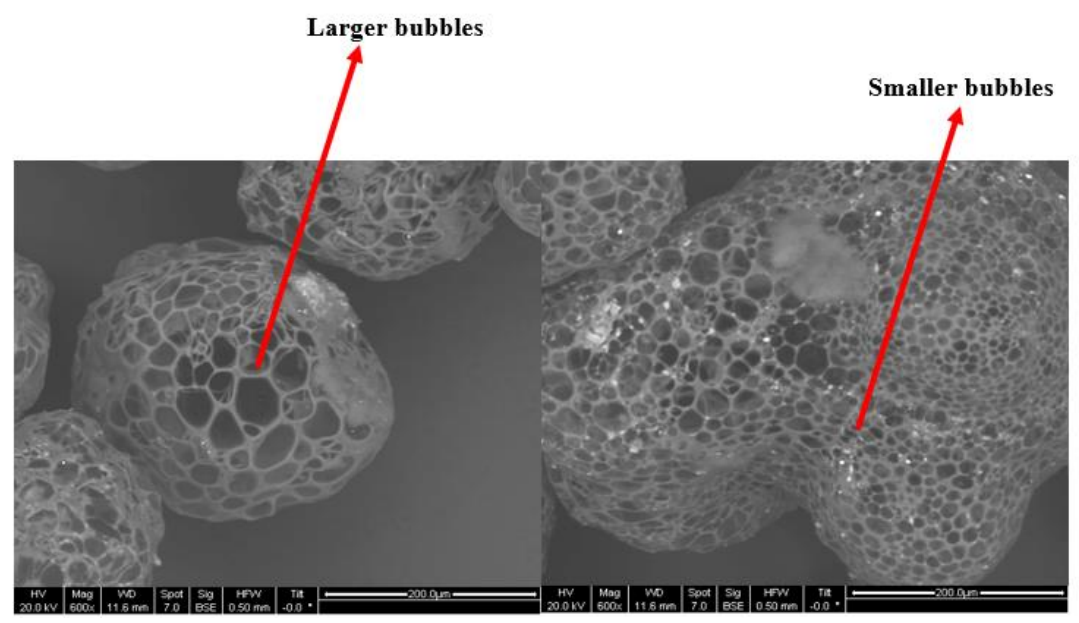

Figure 4. SEM images of chars generated at 6.2 bar (left) and 21.7 bar (right).

Unlike morphology, surface area showed a twofold increase from 109 to $332 \mathrm{~m}^{2} / \mathrm{g}$ as the pressure was increased from 3.4 to 11.3 bar (shown in Table 3). With further increase in pressure to 15.5 bar, the surface area decreased to $289 \mathrm{~m}^{2} / \mathrm{g}$ and reduced further to $170 \mathrm{~m}^{2} / \mathrm{g}$ at 21.7 bar. Interestingly, the surface area for chars generated over a range of pressures, reported in this study was much higher than the surface area of Pittsburgh No.8 coal char reported by Zeng and Fletcher [13]. Zeng and Fletcher generated char under pyrolysis conditions, while the current study used $\mathrm{CO}_{2} / \mathrm{N}_{2}$ to generate chars. The higher surface area is likely due to $\mathrm{CO}_{2}$ reaction with char that created new surface area. Like surface area, a similar trend was also observed for pore volume, where it increased from 0.14 to $0.30 \mathrm{cc} / \mathrm{g}$ as pressure was increased from 3.4 to 11.3 bar and reduced to $0.19 \mathrm{cc} / \mathrm{g}$ with further increase in pressure up to 21.7 bar (shown in Figure 3D). The rapid increase in surface area and pore volume with increase in pressure up to 11.3 bar can be attributed to the opening of pores of size $<50 \AA$. Analysis of pore size distribution shown in Figure $3 \mathrm{E}$ shows that the pore volume in the size $<50 \AA$ increased by $\approx 192 \%$ as the pressure was increased from $3.4(0.042 \mathrm{cc} / \mathrm{g})$ to $11.3 \mathrm{bar}(0.123 \mathrm{cc} / \mathrm{g})$. Correspondingly, the volume in the pores of size $>100 \AA$ increased from 0.078 to $0.116 \mathrm{cc} / \mathrm{g}$. With further increase in pressure to $21.7 \mathrm{bar}$, the volume of the pores of size $<50 \AA$ decreased to $0.065 \mathrm{cc} / \mathrm{g}$, while the volume of the pores of size $>100 \AA$ remained similar (i.e., $0.064 \mathrm{cc} / \mathrm{g}$ ) to that of the char generated at 11.3 bar. The reduction in pore volume in the micropore region (i.e., $<50 \AA$ ) at higher pressures ( 15.5 and 21.7 bar) can be attributed increased mass transfer resistance to volatile release at these pressures.

The effect of pressure on char- $\mathrm{O}_{2}$ reactivity is shown in Figure 5A. The reactivity was obtained on devolatilized chars in the HPTGA. The apparent reactivity was highest for the char generated at 6.2 bar $\left(0.0188 \mathrm{~min}^{-1}\right)$, while the chars generated at other pressures showed similar reactivities ranging between 0.0115 (for 3.4 bar char) and $0.0142 \mathrm{~min}^{-1}$ (21.7 bar char). Normalizing the apparent reactivity with the $\mathrm{N}_{2}$ surface area (i.e., intrinsic reactivity) obtained on the chars in the HPTGA showed that the intrinsic reactivity ranged between $3.0 \times 10^{-5}$ and $5.3 \times 10^{-5} \mathrm{~g} \mathrm{~m}^{-2} \mathrm{~min}^{-1}$. The result shows that pressure has no clear effect on the intrinsic reactivity. The intrinsic reactivity range reported in this work is larger than the intrinsic reactivity range reported for chars generated at higher pressures in other studies $[10,13,15]$. While the other investigations used $\mathrm{CO}_{2}$ surface area to determine the intrinsic reactivity, this study used $\mathrm{N}_{2}$ surface area. 

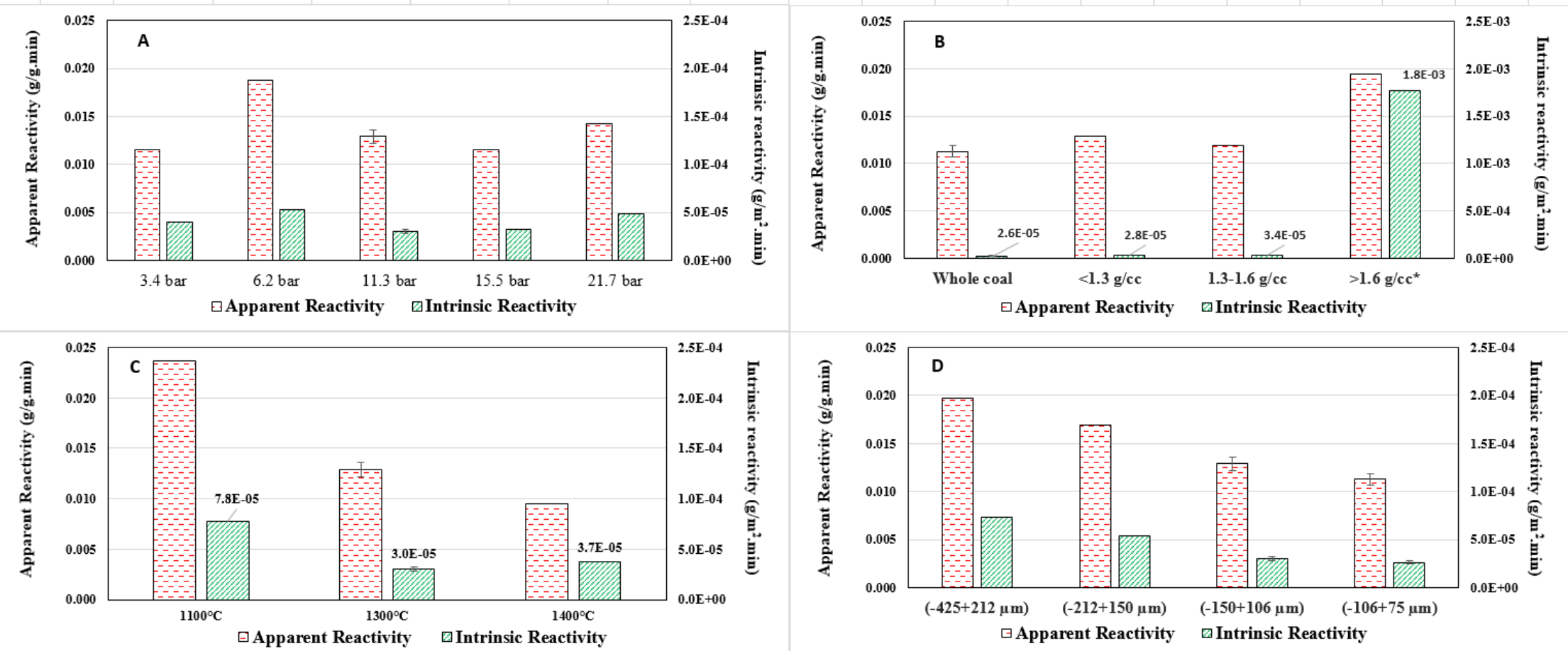

Figure 5. Intrinsic and apparent reactivities of chars; (A) effect of reactor pressure, (B) effect of feed particle density, (C) effect of temperature, (D) effect of feed particle size (intrinsic reactivity was determined by normalizing the apparent reactivity with $\mathrm{N}_{2}$ surface area determined on chars that were further devolatilized at $950{ }^{\circ} \mathrm{C}$ ). Intrinsic reactivity for the char from $>1.6 \mathrm{~g} / \mathrm{cc}$ fraction was determined at $400{ }^{\circ} \mathrm{C}$ in $\mathrm{O}_{2}$ without heating it to $950{ }^{\circ} \mathrm{C}$. 


\subsection{Effect of Feed Particle Density}

The effect of feed particle density was studied using three density fractions (i.e., $<1.3,1.3-1.6$, and $>1.6 \mathrm{~g} / \mathrm{cc}$ ) of the $-106+75 \mu \mathrm{m}$ sample size fraction. The total conversion on a dry-ash free basis of different feed density fractions at $1300{ }^{\circ} \mathrm{C}$ and 11.3 bar is shown in Figure 6A. Interestingly, the conversion was highest $(\approx 83 \%)$ for the $>1.6 \mathrm{~g} / \mathrm{cc}$ fraction, while the conversion for the 1.3-1.6 and $>1.6 \mathrm{~g} / \mathrm{cc}$ fractions were similar $(\approx 65 \%)$. An earlier study with $>1.6 \mathrm{~g} / \mathrm{cc}$ fraction at $1500{ }^{\circ} \mathrm{C} / 1$ bar showed significant amount of meltphase formation that covered the carbonaceous matter [33]. Although the amount of melt phase formation was expected to be much lower due to lower experimental temperature (i.e., $1300{ }^{\circ} \mathrm{C}$ ) in this study, higher conversion was not expected. One of the reasons for higher conversion could be due to absence of highly ordered soot on the char surface. Presence of soot on the chars from low- and medium-density fractions seemed to have affected their gasification reactivity in HPHTFR. The HRTEM pictures presented in Figure 7 confirmed the presence of soot for chars from low- and medium-density fractions. Soot was not observed for the sample generated from the high-density fraction. Absence of soot deposition could be due to variation in vitrinite content. Analysis of the density fractions of the Pittsburgh no. 8 coal for maceral composition, reported elsewhere [16], revealed that the highest density fraction had about 50 vol.\% inertinite, while low- and medium-density fractions were rich $(>75 \mathrm{vol} . \%)$ in liptinite and vitrinite combined. Vitrinite content is known to increase fluidity at higher pressures. The fluid (tar) tends to contain highly aromatic compounds which gets converted to soot due to polymerization reactions [34,35].

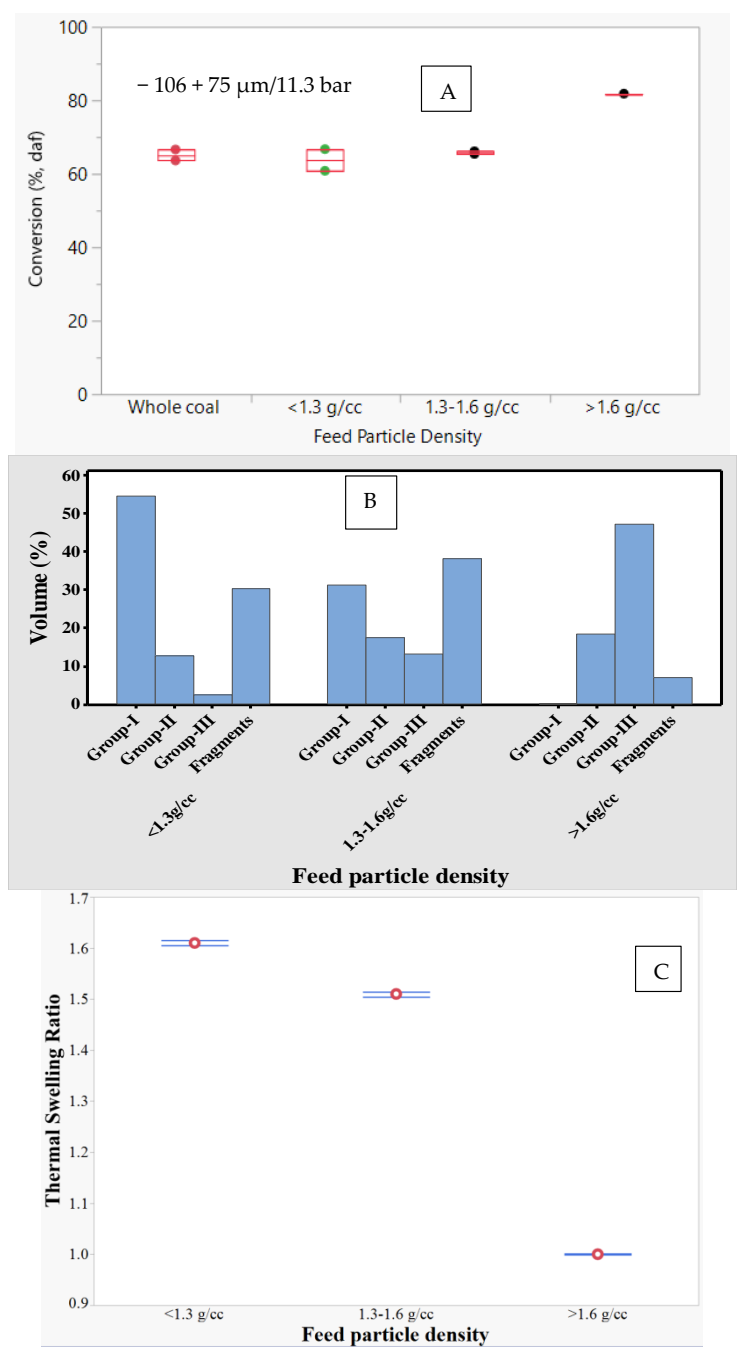

Figure 6. Cont. 


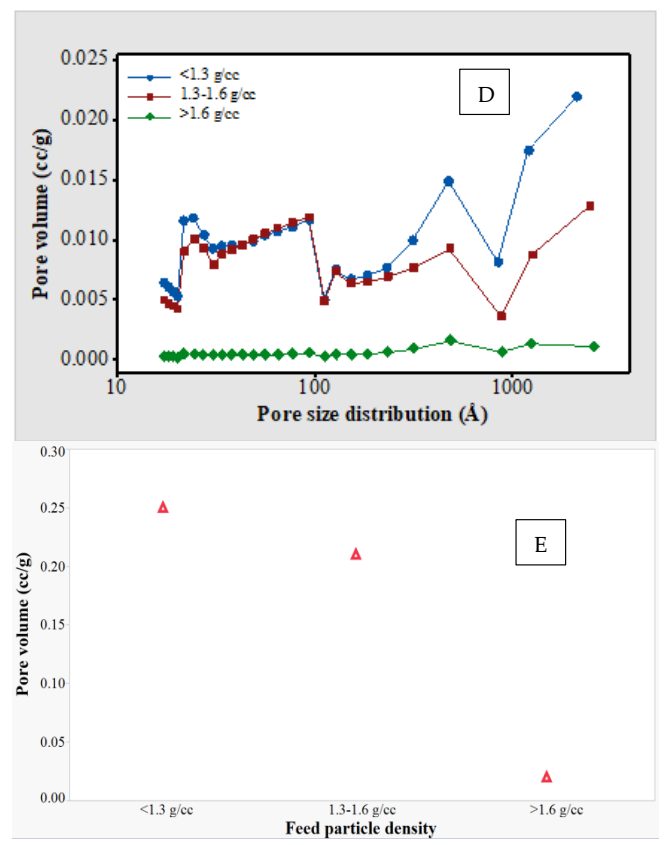

Figure 6. Effect of feed particle density on (A) coal conversion (95\% CI: $\pm 8.2 \%$ ), (B) morphology, (C) thermal swelling ratio, (D) pore size distribution, (E) pore volume (whole coal of $-106+75 \mu \mathrm{m}$ size fraction).

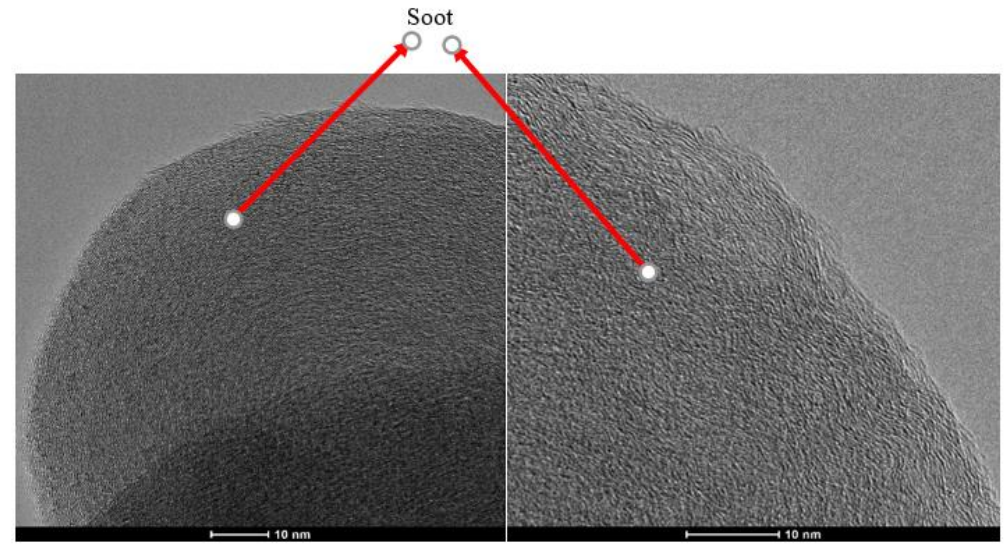

Figure 7. HRTEM pictures of soot: $<1.3 \mathrm{~g} / \mathrm{cc}$ char (left) $1.3-1.6 \mathrm{~g} / \mathrm{cc}$ char (right).

Table 3 and Figure 6B-E show the thermal swelling ratio, morphology, surface area, and pore size distribution of chars for $<1.3,1.3-1.6$, and $>1.6 \mathrm{~g} / \mathrm{cc}$ fractions. Increase in feed particle density decreased the thermal swelling ratio from 1.61 to 1.00 , surface area from 327 to $11 \mathrm{~m}^{2} / \mathrm{g}$, group-I char concentration from $55 \%$ to $0 \%$, and pore volume from 0.25 to $0.02 \mathrm{cc} / \mathrm{g}$. Some of these results are in agreement with the observations made by Yu et al. [17], who also showed that for Australian coals, both porosity and group-I char concentration decreased with increase in feed particle density. Variation in maceral content and inorganic matter concentration over various density fractions were shown to affect swelling [36]. In the current study, higher vitrinite content ( $>70$ vol.\%) in low- and medium-density fractions implies higher fluidity, and consequently higher group-I char formation, surface area, and pore volume. Unlike vitrinite, inertinite does not develop much fluidity and hence does not generate high-porosity and high surface area char [36]. Hence, the high-density fraction, with $\approx 50 \%$ inertinite, generated about $50 \%$ group-III char with no group-I char. Besides maceral content, the inorganic matter increased with feed particle density. It was suggested that ash grains in the char can reduce the fluidity of a particle and thereby preventing the entire particle from swelling [30,36,37]. 
Absence of swelling means there is no substantial surface area or pore volume generated during gasification of the highest density fraction.

Figure 5B shows the apparent and intrinsic reactivities of chars. The apparent reactivity was highest for the char generated from the high-density fraction, while the chars generated from lowand medium-density fractions were relatively less reactive. Correspondingly, char surface area and pore volume decreased with increase in feed particle density. These imply that the char from the high-density fraction is structurally more reactive than that of chars from low- and medium-density fractions. The lower reactivity for the char from the low-density fraction could be due to increased structural ordering. The vitrinite content, which is known to cause fluidity and eventually structural ordering, increased with decrease in feed particle density. The reflectance microscopy analysis showed that the inertinite-derived section of the char was qualitatively found to be isotropic in nature with random reflectance of $<5 \%$, while the vitrinite-derived section of the char showed reflectance of $>6.5 \%$. Some particles from low- and medium-density fractions showed the presence of pyrolytic carbon $(>10 \%)$. The higher reflectance is indicative of higher structural ordering. The random reflectance of the high-density fraction was not reported in Table 3 due to the unavailability of vitrinite-derived portions in the char. The high degree of structural ordering seemed to have contributed to lower intrinsic reactivity for the char derived from the low-density fraction.

\subsection{Effect of Temperature}

The effect of temperature on conversion was investigated by generating chars from the $-150+$ $106 \mu \mathrm{m}$ fraction at 11.3 bar and three different temperatures $\left(1100 \pm 13,1300 \pm 15\right.$, and $\left.1400 \pm 10^{\circ} \mathrm{C}\right)$. These temperatures were chosen to cover the temperature range typically found in the second stage of a slurry-fed entrained flow gasifier [38]. As Figure 8A shows, the increase in temperature from 1100 to $1400{ }^{\circ} \mathrm{C}$ increased the conversion from $30 \pm 8.2$ to $70 \pm 8.2 \mathrm{wt} . \%$. Notably, the char generated at $1100{ }^{\circ} \mathrm{C}$ is in the early gasification stage ( $<50 \%$ conversion), while the chars generated at 1300 and $1400{ }^{\circ} \mathrm{C}$ were in the middle ( $50 \%-70 \%$ conversion) and late gasification ( $>70 \%$ conversion) stages, respectively.

Figure $8 B, C$ shows the effect of temperature on morphology and thermal swelling ratio. As the temperature was increased, the thermal swelling ratio decreased marginally from 1.68 for $1100{ }^{\circ} \mathrm{C}$ char to 1.65 for $1300^{\circ} \mathrm{C}$ char. The thermal swelling ratio is inversely proportional to the apparent density ratio of char to coal, and mass loss (shown in Equation (3)).

It can also be seen from Figure $8 \mathrm{~B}$ that fragmentation is significantly higher for char generated at $1300{ }^{\circ} \mathrm{C}$. Gale et al. suggested that fragmentation can reduce thermal swelling ratio [39]. As fragmentation increases, the char packing factor also increases and consequently the apparent density ratio of char to feed. Secondly, the conversion for $1300{ }^{\circ} \mathrm{C}$ char $(\approx 58 \%)$ was much higher than that of $1100{ }^{\circ} \mathrm{C}$ char $(\approx 30 \%)$. Despite higher conversion (ash content) and fragmentation, the thermal swelling ratio of the char generated at $1300^{\circ} \mathrm{C}$ is not very different from the char generated at $1100{ }^{\circ} \mathrm{C}$. This shows the thermal swelling ratio at given conversion increases with temperature up to $1300^{\circ} \mathrm{C}$. With further increase in temperature to $1400^{\circ} \mathrm{C}$, the thermal swelling ratio dropped substantially to 1.38. The decrease in thermal swelling ratio above $1300^{\circ} \mathrm{C}$ can be attributed to increased conversion (or ash), and fragmentation. Increased fragmentation with temperature can mostly be attributed to pore enlargement and pore overlapping due to internal reaction with conversion causing thinning and ultimately breaking of the wall structure [26].

Unlike thermal swelling ratio, temperature showed a significant effect on surface area and pore volume (shown in Table 3 and Figure 8E). The surface area and pore volume increased dramatically by a factor of 46 and 14, respectively, as temperature was increased from 1100 to $1300{ }^{\circ} \mathrm{C}$. However, with further increase in temperature to $1400^{\circ} \mathrm{C}$, the surface area and pore volume decreased by $\approx 60 \%$ and $\approx 53 \%$ of $1300{ }^{\circ} \mathrm{C}$ char, respectively. It is important to remember that the conversion for the char generated at $1400{ }^{\circ} \mathrm{C}$ was above $70 \%$. It is known that beyond a certain conversion (typically $>60 \%$ ), the pores of the chars collapse and merge, leading to lowered surface area and pore volume [40]. 
Higher conversion and higher fragmentation for $1400^{\circ} \mathrm{C}$ char seemed to have reduced the surface area and the pore volume.
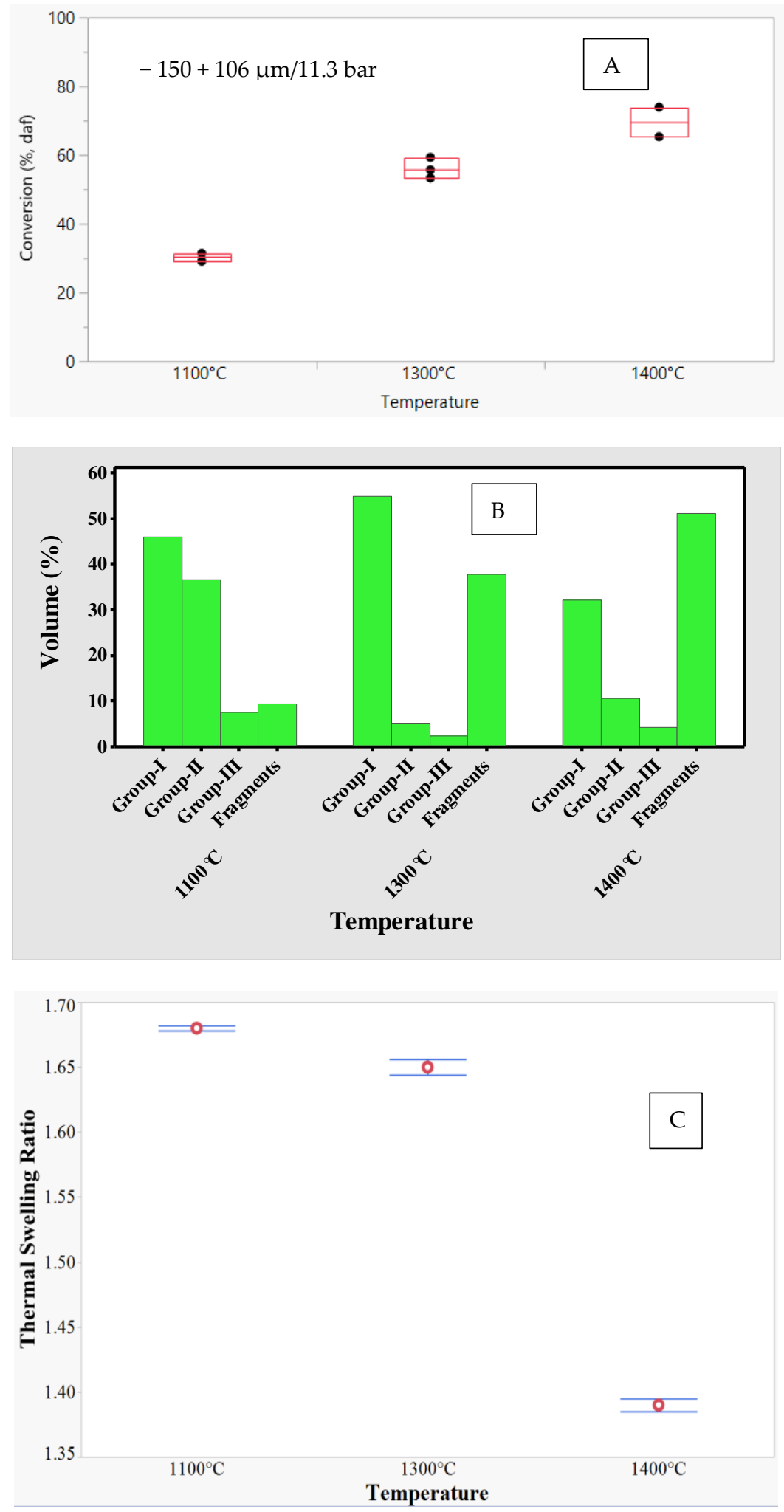

Figure 8. Cont. 

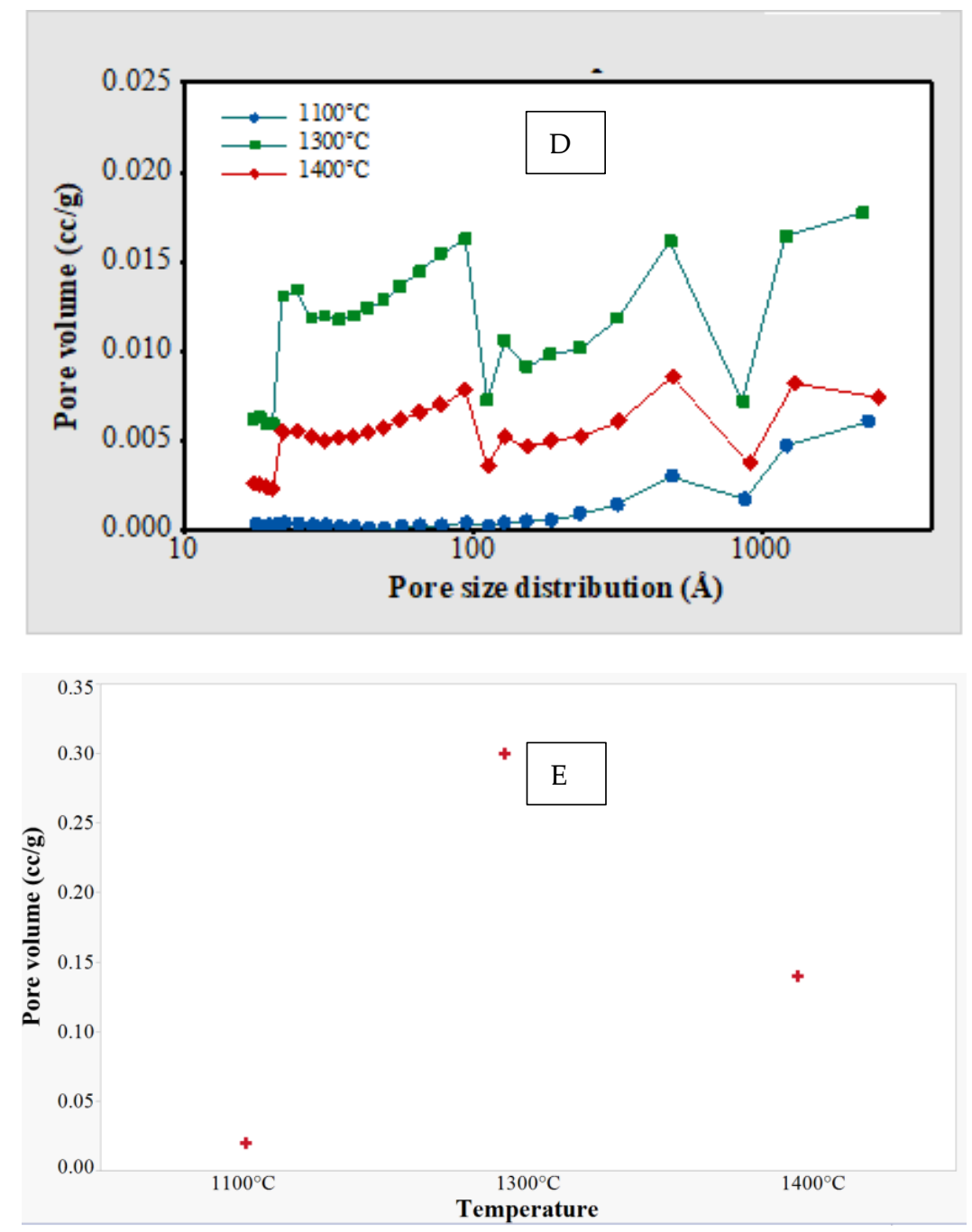

Figure 8. Effect of temperature on (A) coal conversion (95\% CI: $\pm 8.2 \%)$, (B) morphology, (C) thermal swelling ratio, (D) pore size distribution, (E) pore volume.

Char generation temperature showed a significant effect on char reactivity, with apparent reactivity decreased by $\approx 59 \%$ from $23.7 \times 10^{-3} \mathrm{~min}^{-1}$ for $1100{ }^{\circ} \mathrm{C}$ char to $9.6 \times 10^{-3} \mathrm{~min}^{-1}$ for $1400{ }^{\circ} \mathrm{C}$ char (shown in Figure 5C). Normalizing the apparent reactivity with the surface area also showed that there was a significant drop in intrinsic reactivity from $7.8 \times 10^{-5} \mathrm{gm}^{-2} \mathrm{~min}^{-1}$ for $1100^{\circ} \mathrm{C}$ char to $3.0 \times 10^{-5}$ $\mathrm{gm}^{-2} \mathrm{~min}^{-1}$ for $1300{ }^{\circ} \mathrm{C}$ char, and the intrinsic reactivity slightly increased to $3.7 \times 10^{-5} \mathrm{gm}^{-2} \mathrm{~min}^{-1}$ at $1400{ }^{\circ} \mathrm{C}$. Previous studies also observed similar trends where the intrinsic reactivity decreased with increase in char generation temperature [41,42]. In this investigation, however, the intrinsic reactivities of chars generated at 1300 and $1400{ }^{\circ} \mathrm{C}$ are not very different. Tremel et al. also showed that above $2 \mathrm{~s}$ residence time, temperature does not significantly affect the intrinsic reactivity [15].

The significant drop in reactivity at higher temperatures could be due to increased structural ordering. The chars were characterized for structural ordering through random reflectance. The random reflectance showed a significant increase from $6.86 \% \pm 0.23 \%$ for $1100{ }^{\circ} \mathrm{C}$ char to $8.03 \% \pm 0.45 \%$ for 1300 ${ }^{\circ} \mathrm{C}$. However, further increase in temperature to $1400{ }^{\circ} \mathrm{C}$ did not increase the reflectance significantly (i.e., $8.16 \% \pm 0.41 \%$ ). Reflectance analysis showed that some of the particles, from 1300 and $1400{ }^{\circ} \mathrm{C}$ chars, had pyrolytic carbon with very high reflectance $(>10 \%)$. Presence of pyrolytic carbon is an indication of graphitization. All these point to increased structural ordering and graphitization for the decline in reactivity for chars generated at 1300 and $1400{ }^{\circ} \mathrm{C}$. 


\subsection{Effect of Feed Particle Size}

The effect of initial coal particle size on conversion was studied on chars produced from four particle size fractions $-106+75,-150+106,-212+150$, and $-425+212 \mu \mathrm{m}$-generated at $1300{ }^{\circ} \mathrm{C}$ and 11.3 bar. The conversion decreased from $\approx 65 \%$ to $38 \%$ as particle size increased from $-106+75$ to $-425+212 \mu \mathrm{m}$ (shown in Figure 9A). The reduction in conversion with particle size can be attributed to increased diffusional resistance for reaction gas into char particles. Interestingly, the amount of residual volatile matter in the char also did not vary much with increase in feed particle size. Higher amount of volatile matter left in the char from the finest particle size fraction, despite higher conversion, suggests that the higher fluidity for that size fraction generated during pyrolysis.

Table 3 and Figure 9B-E show the effect of initial particle size on thermal swelling ratio, surface area, and pore volume. As the feed particle size fraction increased from $-106+75$ to $-425+212 \mu \mathrm{m}$, the char surface area and pore volume decreased from 333 to $119 \mathrm{~m}^{2} / \mathrm{g}$, and 0.30 to $0.08 \mathrm{cc} / \mathrm{g}$, respectively. The difference in surface area and pore volume can be attributed to difference in organic composition. A study conducted by Hower showed that brittle microlithotypes, such as vitrite, are likely to partition to finer sizes, while hard-to-grind microlithotypes rich in inertinite and liptinite are likely to concentrate in the coarse-sized fractions $(>150 \mu \mathrm{m})$ [43]. The presence of higher concentration of non-caking inertinite as a part of multi-maceral microlithotype in a larger coal particle may have led to reduced fluidity and consequently reduction in group-I char concentration, surface area, and pore volume for coarse-sized fractions (i.e., $-212+150$ and $-425+212 \mu \mathrm{m}$ ). Interestingly, the particle size marginally affected the char swelling ratio as it increased from 1.58 for the char from $-425+212 \mu \mathrm{m}$ fraction to 1.65 for the char from $-150+106 \mu \mathrm{m}$ fraction. Earlier studies under pyrolysis observed that swelling (or porosity) decreased with an increase in coal particle size [17,44,45]. It is important to recognize that chars from the coarser size fractions are in early stages of conversion $(<50 \%)$, while the chars from the fine-sized fractions (i.e., $-106+75$ and $-150+106 \mu \mathrm{m})$ are in middle stages of conversion $(50 \%-70 \%)$. Moreover, the extent of fragmentation of chars from the finer size fractions are much higher than the chars from the coarser size fractions. Fragmentation increases the packing factor, while the conversion is known to increase the density of chars and consequently reduce thermal swelling ratio. However, for a given conversion, it is likely that the particle size inversely affects the thermal swelling ratio.

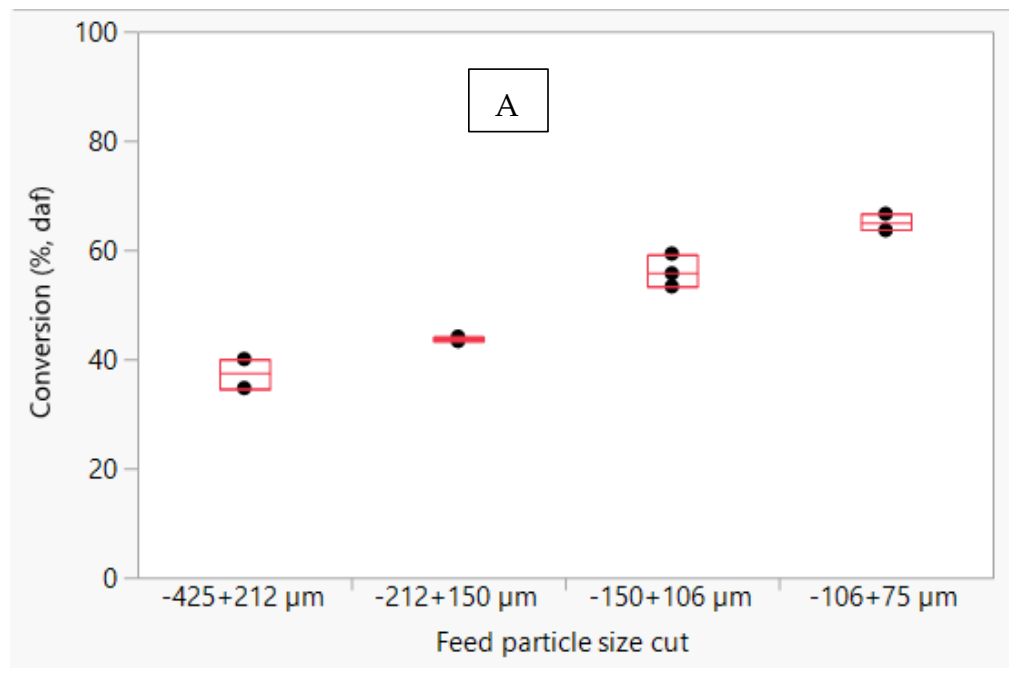

Figure 9. Cont. 

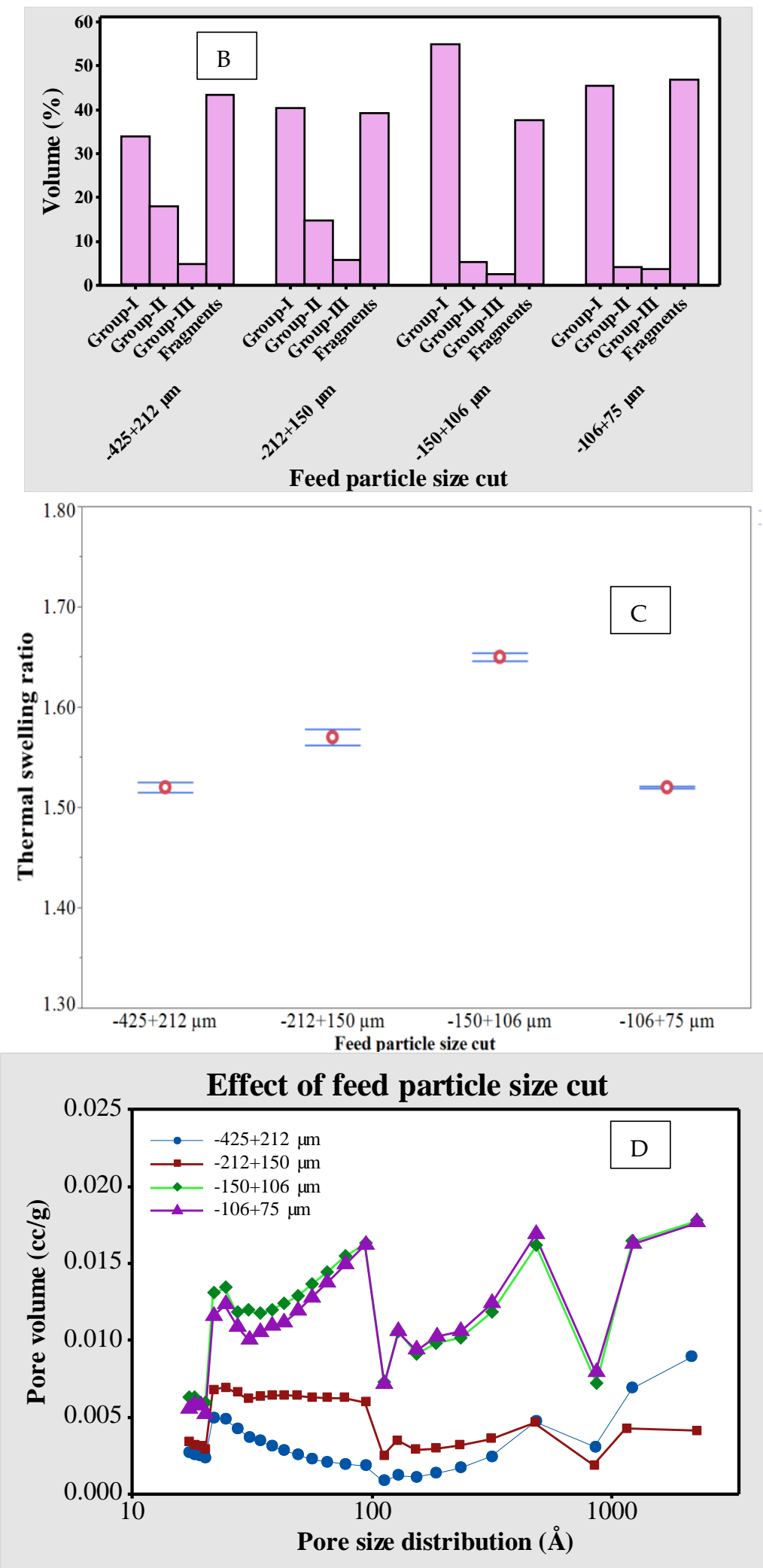

Figure 9. Cont. 


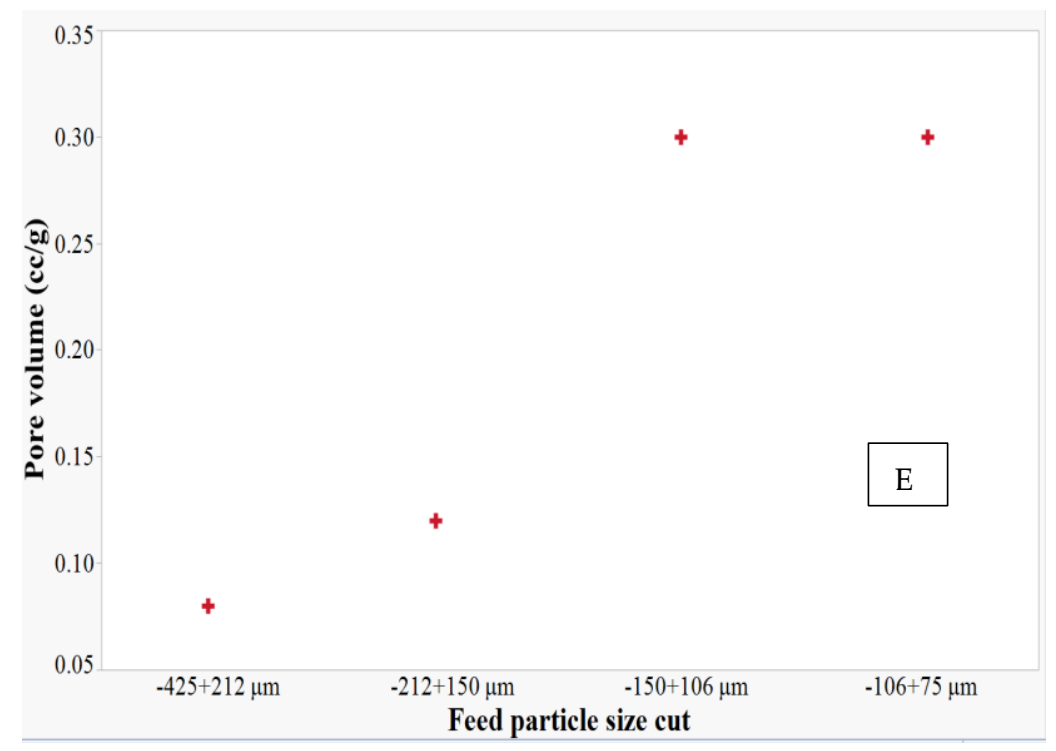

Figure 9. Effect of feed particle size cut on (A) coal conversion (95\% CI: $\pm 8.2 \%$ ), (B) morphology, (C) thermal swelling ratio, (D) pore size distribution, (E) pore volume.

The effects of initial feed particle size on apparent and intrinsic reactivities are shown in Figure 5D. The apparent reactivity increased with particle size. The notable observation is that reactivities of chars generated from the fine-sized fractions were closer compared with reactivities of chars from the coarse-sized fractions. This trend is also visible in pore size distribution, and surface area (shown in Table 3 and Figure 9D). It appears that the organic composition (i.e., maceral composition) among fine-sized fractions are more similar compared to the maceral composition of the coarse-sized fractions. Lower surface areas and higher apparent reactivities for chars from the coarse-size fractions mean the chars are structurally more reactive. For the chars from the fine-sized fractions, there is a predominant effect of structural ordering leading to reorganization of carbon atoms which is reflected by the higher random reflectance ( $~ 8 \%$ for chars from $-106+75$ and $-150+106 \mu \mathrm{m}$ size fractions). The reorganization of carbon would only occur with the vitrinite-derived portion of the feed due to its ability to generate tars. Once the hydrogen is removed from the tars as volatiles, the tars undergo retrogressive reactions leading to increased structural ordering. Higher concentration of inertinite derivative in the char and limited fluidity (reflected by higher group-II concentration as shown in Figure 9B) from the coarse-sized particle size distributions mean lower structural reordering. This explanation is supported by the lower random reflectance for the chars (shown in Table 3 ) derived from the coarse-sized fractions $(\approx 7 \%$ for chars from $-212+150$ and $-425+212 \mu \mathrm{m}$ size fractions).

\section{Statistical Analysis}

The effects of temperature, pressure, feed particle size, and feed particle density on conversion, structural characteristics (i.e., pore volume, surface area, thermal swelling ratio, and group-I char) and the intrinsic reactivity were statistically evaluated based on $F$-test of overall regression model in Minitab software. An $F$ statistic is the ratio of variation between sample means to variation within sample means. The null hypothesis assumes none of the parameters affect conversion, structural characteristics, and intrinsic reactivity. The null hypothesis must be rejected when the $p$-value of an $F$-test is $<0.025$ and this is based on $95 \%$ confidence interval. The effects of various parameters (i.e., temperature, pressure, feed particle size, and feed particle density) on conversion were statistically determined and reported in Table 4. From the $p$-values, the conversion is most affected by temperature followed by particle size. Pressure and feed particle density showed no significant effect on conversion due to large uncertainty. Similarly, the effects of these parameters on group-I char concentration and thermal swelling ratio were statistically determined and reported in Table 5. Feed particle density is 
the only factor that was found to statistically affect the group-I char formation. In the case of thermal swelling ratio, both feed particle density and pressure showed significant effects. It is interesting to note that the pressure affects thermal swelling ratio, while it has insignificant effect on group-I char concentration. This is because Pittsburgh no. 8 coal generates a higher amount of fluidity at lower pressures to form large concentrations of highly porous char (or group-I char). Further increase in pressure increases the swelling ratio without affecting the group-I char concentration. The insignificant effect of pressure, particle size, and temperature can be attributed to high uncertainty in group-I char concentration data $( \pm 6.8 \%$ error).

Table 4. Effects of various parameters on conversion.

\begin{tabular}{ccc}
\hline Predictor & $\boldsymbol{F}$-Value & $\boldsymbol{p}$-Value \\
\hline Pressure & 7.1 & 0.033 \\
Particle Density & 2.7 & 0.133 \\
Temperature & 43.0 & 0.001 \\
Particle Size & 13.3 & 0.008 \\
\hline
\end{tabular}

Table 5. Effects of various parameters on group-I char concentration and thermal swelling ratio.

\begin{tabular}{ccccc}
\hline Predictor & \multicolumn{2}{c}{ Group-I Char Concentration } & \multicolumn{2}{c}{ Thermal Swelling Ratio } \\
\hline & $\boldsymbol{F}$-Value & $\boldsymbol{p}$-Value & $\boldsymbol{F}$-Value & $\boldsymbol{p}$-Value \\
\hline Pressure & 0.1 & 0.730 & 8.4 & 0.023 \\
Particle Density & 12.4 & 0.003 & 11.81 & 0.003 \\
Temperature & 0.7 & 0.439 & 4.41 & 0.074 \\
Particle Size & 3.1 & 0.120 & 0.0 & 0.910 \\
\hline
\end{tabular}

While pressure has an insignificant effect of group-I char concentration, feed particle density showed effects on both group-I concentration and swelling ratio. This is attributed to significant reduction in vitrinite content with feed particle density as vitrinite content is closely associated with fluidity and thermal swelling ratio.

The effects on intrinsic reactivity are presented in Table 6 . Feed particle density has the highest effect on the intrinsic reactivity, followed by temperature, and feed particle size. Variation in maceral content (vitrinite content) with particle size, and feed particle density affected the char chemical structure and consequently the intrinsic reactivity. In the case of temperature, higher conversion for chars have affected the reactivity. For the char generated at $1100^{\circ} \mathrm{C}$, the intrinsic reactivity was much higher compared to chars generated at 1300 and $1400{ }^{\circ} \mathrm{C}$.

Table 6. Effects of various parameters on intrinsic reactivity.

\begin{tabular}{ccc}
\hline Predictor & \multicolumn{2}{c}{ Intrinsic } \\
\hline & $\boldsymbol{F}$-Value & $\boldsymbol{p}$-Value \\
\hline Pressure & 0.01 & 0.932 \\
Particle Density & 7795 & 0.000 \\
Temperature & 12.51 & 0.012 \\
Particle Size & 9.52 & 0.022 \\
\hline
\end{tabular}

\section{Summary and Conclusions}

The effects of particle size, inorganic matter, temperature, and pressure on structural properties and reactivities of Pittsburgh No. 8 coal were studied under gasification conditions. The char-ash particles were analyzed for conversion, reactivity, group-I char concentration, and thermal swelling ratio. Based on the investigations, the following summary and conclusions were drawn: 
- Among the parameters tested, temperature has the maximum effect on coal conversion, followed by particle size, pressure, and feed particle density.

- $\quad$ Feed particle density showed the highest effect on the group-I char formation, with low-density particles generating higher concentration of highly porous group-I chars. Group-I char concentration was found to correlate with vitrinite content. The other factors such as particle size, temperature, and pressure were not found to significantly affect the group-I char concentration.

- Thermal swelling ratio is affected by both pressure and feed particle density. Other factors such as temperature and particle size showed no statistically significant effect on thermal swelling ratio. Lack of a clear effect of temperature and particle size on thermal swelling ratio can be attributed to different conversion levels of chars.

- Intrinsic reactivity is affected by all parameters except pressure. Pressure affects the structural features such as thermal swelling ratio and surface area and not the chemical reactivity. The effect of the four parameters on intrinsic reactivity follows the order: feed particle density $>$ temperature $>$ feed particle size $>$ pressure.

Author Contributions: V.K. has conducted the experimental investigation under the supervision of S.V.P. Both authors reviewed and discussed the results and the final manuscript.

Funding: This research received no external funding. This is conducted as a part of doctoral work of V.K.

Acknowledgments: The authors would like to thank Gareth Mitchell for his help with reflectance microscopy and morphological analysis of chars.

Conflicts of Interest: The authors declare that there is no conflict of interest.

\section{References}

1. Krishnamoorthy, V.; Pisupati, S. A Critical Review of Mineral Matter Related Issues during Gasification of Coal in Fixed, Fluidized, and Entrained Flow Gasifiers. Energies 2015, 8, 10430-10463. [CrossRef]

2. Pisupati, S.V.; Krishnamoorthy, V. 2-Utilization of coal in IGCC systems. In Integrated Gasification Combined Cycle (IGCC) Technologies; Wang, T., Stiegel, G., Eds.; Woodhead Publishing: Cambridge, UK, 2017; pp. 83-120. [CrossRef]

3. Roberts, D.G.; Hodge, E.M.; Harris, D.J.; Stubington, J.F. Kinetics of Char Gasification with $\mathrm{CO}_{2}$ under Regime II Conditions: Effects of Temperature, Reactant, and Total Pressure. Energy Fuels 2010, 24, 5300-5308. [CrossRef]

4. Hodge, E.M.; Roberts, D.G.; Harris, D.J.; Stubington, J.F. The Significance of Char Morphology to the Analysis of High-Temperature Char- $\mathrm{CO}_{2}$ Reaction Rates. Energy Fuels 2010, 24, 100-107. [CrossRef]

5. Lee, C.W.; Jenkins, R.G.; Schobert, H.H. Structure and reactivity of char from elevated pressure pyrolysis of Illinois No. 6 bituminous coal. Energy Fuels 1992, 6, 40-47. [CrossRef]

6. Lee, C.W.; Jenkins, R.G.; Schobert, H.H. Mechanisms and kinetics of rapid, elevated pressure pyrolysis of Illinois No. 6 bituminous coal. Energy Fuels 1991, 5, 547-555. [CrossRef]

7. Kajitani, S.; Hara, S.; Matsuda, H. Gasification rate analysis of coal char with a pressurized drop tube furnace. Fuel 2002, 81, 539-546. [CrossRef]

8. Kajitani, S.; Suzuki, N.; Ashizawa, M.; Hara, S. $\mathrm{CO}_{2}$ gasification rate analysis of coal char in entrained flow coal gasifier. Fuel 2006, 85, 163-169. [CrossRef]

9. Ahn, D.H.; Gibbs, B.M.; Ko, K.H.; Kim, J.J. Gasification kinetics of an Indonesian sub-bituminous coal-char with $\mathrm{CO}_{2}$ at elevated pressure. Fuel 2001, 80, 1651-1658. [CrossRef]

10. Benfell, K.E.; Liu, G.-S.; Roberts, D.G.; Harris, D.J.; Lucas, J.A.; Bailey, J.G.; Wall, T.F. Modeling char combustion: The influence of parent coal petrography and pyrolysis pressure on the structure and intrinsic reactivity of its char. Proc. Combust. Inst. 2000, 28, 2233-2241. [CrossRef]

11. Krishnamoorthy, V.; Krishnamurthy, N.; Pisupati, S.V. Intrinsic gasification kinetics of coal chars generated in a high-pressure, high-temperature flow reactor. Chem. Eng. J. 2019, 375, 122028. [CrossRef]

12. Krishnamoorthy, V.; Yeboah, Y.D.; Pisupati, S.V. Influence of Pyrolysis Gas on Volatile Yield and $\mathrm{CO}_{2}$ Reaction Kinetics of the Char Samples Generated in a High-Pressure, High-Temperature Flow Reactor. Energies 2018, 12, 107. [CrossRef] 
13. Zeng, D.; Fletcher, T.H. Effects of Pressure on Coal Pyrolysis and Char Morphology. Energy Fuels 2005, 19, 1828-1838. [CrossRef]

14. Yu, J.; Harris, D.; Lucas, J.; Roberts, D.; Wu, H.; Wall, T. Effect of Pressure on Char Formation during Pyrolysis of Pulverized Coal. Energy Fuels 2004, 18, 1346-1353. [CrossRef]

15. Tremel, A.; Haselsteiner, T.; Nakonz, M.; Spliethoff, H. Coal and char properties in high temperature entrained flow gasification. Energy 2012, 45, 176-182. [CrossRef]

16. Soundarrajan, N.; Krishnamurthy, N.; Pisupati, S. Characterization of Size and Density Separated Fractions of a Bituminous Coal as a Feedstock for Entrained Slagging Gasification. Int. J. Clean Coal Energy 2013, 2, 58-67. [CrossRef]

17. Yu, J.; Lucas, J.; Strezov, V.; Wall, T. Swelling and Char Structures from Density Fractions of Pulverized Coal. Energy Fuels 2003, 17, 1160-1174. [CrossRef]

18. Krishnamoorthy, V.; Pisupati, S.V. Fate of Sulfur during Entrained-Flow Gasification of Pittsburgh No. 8 Coal: Influence of Particle Size, Sulfur Forms, and Temperature. Energy Fuels 2016, 30, 3241-3250. [CrossRef]

19. Guillen, M.D.; Blanco, J.; Canga, J.S.; Blanco, C.G. Study of the effectiveness of 27 organic solvents in the extraction of coal tar pitches. Energy Fuels 1991, 5, 188-192. [CrossRef]

20. Krishnamoorthy, V. Structural Characteristics and $\mathrm{CO}_{2}$ Reactivity of Partially Gasified Pittsburgh No.8 Coal Chars Generated in a High-Pressure, High-Temperature, Laminar-Flow Reactor. Ph.D. Thesis, The Pennsylvania State University, University Park, PA, USA, 2018.

21. Fletcher, T.H. Swelling properties of coal chars during rapid pyrolysis and combustion. Fuel 1993, 72, 1485-1495. [CrossRef]

22. Lester, E.; Alvarez, D.; Borrego, A.G.; Valentim, B.; Flores, D.; Clift, D.A.; Rosenberg, P.; Kwiecinska, B.; Barranco, R.; Petersen, H.I.; et al. The procedure used to develop a coal char classification-Commission III Combustion Working Group of the International Committee for Coal and Organic Petrology. Int. J. Coal Geol. 2010, 81, 333-342. [CrossRef]

23. Alvarez, D.; Borrego, A.G.; Menéndez, R. Unbiased methods for the morphological description of char structures. Fuel 1997, 76, 1241-1248. [CrossRef]

24. Bailey, J.G.; Tate, A.; Diessel, C.F.K.; Wall, T.F. A char morphology system with applications to coal combustion. Fuel 1990, 69, 225-239. [CrossRef]

25. Gilfillan, A.; Lester, E.; Cloke, M.; Snape, C. The structure and reactivity of density separated coal fractions. Fuel 1999, 78, 1639-1644. [CrossRef]

26. Wall, T.F.; Liu, G.-s.; Wu, H.-w.; Roberts, D.G.; Benfell, K.E.; Gupta, S.; Lucas, J.A.; Harris, D.J. The effects of pressure on coal reactions during pulverised coal combustion and gasification. Prog. Energy Combust. Sci. 2002, 28, 405-433. [CrossRef]

27. Wu, T.; Gong, M.; Lester, E.; Wang, F.; Zhou, Z.; Yu, Z. Characterisation of residual carbon from entrained-bed coal water slurry gasifiers. Fuel 2007, 86, 972-982. [CrossRef]

28. Khan, M.R.; Jenkins, R.G. Swelling and plastic properties of coal devolatilized at elevated pressures: An examination of the influences of coal type. Fuel 1986, 65, 725-731. [CrossRef]

29. Lee, C.W.; Scaroni, A.W.; Jenkins, R.G. Effect of pressure on the devolatilization and swelling behaviour of a softening coal during rapid heating. Fuel 1991, 70, 957-965. [CrossRef]

30. Strezov, V.; Lucas, J.A.; Wall, T.F. Effect of pressure on the swelling of density separated coal particles. Fuel 2005, 84, 1238-1245. [CrossRef]

31. Shurtz, R.C.; Hogge, J.W.; Fowers, K.C.; Sorensen, G.S.; Fletcher, T.H. Coal Swelling Model for Pressurized High Particle Heating Rate Pyrolysis Applications. Energy Fuels 2012, 26, 3612-3627. [CrossRef]

32. Yu, J.L.; Strezov, V.; Lucas, J.; Liu, G.S.; Wall, T. A mechanistic study on char structure evolution during coal devolatilization-Experiments and model predictions. Proc. Combust. Inst. 2002, 29, 467-473. [CrossRef]

33. Krishnamoorthy, V.; Tchapda, A.H.; Pisupati, S.V. A study on fragmentation behavior, inorganic melt phase formation, and carbon loss during high temperature gasification of mineral matter rich fraction of Pittsburgh No. 8 coal. Fuel 2017, 208, 247-259. [CrossRef]

34. Fletcher, T.H.; Ma, J.; Rigby, J.R.; Brown, A.L.; Webb, B.W. Soot in coal combustion systems. Prog. Energy Combust. Sci. 1997, 23, 283-301. [CrossRef]

35. Tchapda, A.H.; Krishnamoorthy, V.; Yeboah, Y.D.; Pisupati, S.V. Analysis of tars formed during co-pyrolysis of coal and biomass at high temperature in carbon dioxide atmosphere. J. Anal. Appl. Pyrolysis 2017, 128, 379-396. [CrossRef] 
36. Yu, J.; Lucas, J.A.; Wall, T.F. Formation of the structure of chars during devolatilization of pulverized coal and its thermoproperties: A review. Prog. Energy Combust. Sci. 2007, 33, 135-170. [CrossRef]

37. Yu, J.; Strezov, V.; Lucas, J.; Wall, T. Swelling behaviour of individual coal particles in the single particle reactor. Fuel 2003, 82, 1977-1987. [CrossRef]

38. Ma, J.; Zitney, S.E. Computational Fluid Dynamic Modeling of Entrained-Flow Gasifiers with Improved Physical and Chemical Submodels. Energy Fuels 2012, 26, 7195-7219. [CrossRef]

39. Gale, T.K.; Bartholomew, C.H.; Fletcher, T.H. Decreases in the swelling and porosity of bituminous coals during devolatilization at high heating rates. Combust. Flame 1995, 100, 94-100. [CrossRef]

40. Bhatia, S.K.; Perlmutter, D.D. A random pore model for fluid-solid reactions: I. Isothermal, kinetic control. AIChE J. 1980, 26, 379-386. [CrossRef]

41. Gale, T.K.; Bartholomew, C.H.; Fletcher, T.H. Effects of Pyrolysis Heating Rate on Intrinsic Reactivities of Coal Chars. Energy Fuels 1996, 10, 766-775. [CrossRef]

42. Fermoso, J.; Stevanov, C.; Moghtaderi, B.; Arias, B.; Pevida, C.; Plaza, M.G.; Rubiera, F.; Pis, J.J. High-pressure gasification reactivity of biomass chars produced at different temperatures. J. Anal. Appl. Pyrolysis 2009, 85, 287-293. [CrossRef]

43. Hower, J.C. Maceral/microlithotype partitioning with particle size of pulverized coal: Examples from power plants burning Central Appalachian and Illinois basin coals. Int. J. Coal Geol. 2008, 73, 213-218. [CrossRef]

44. Gao, H.; Murata, S.; Nomura, M.; Ishigaki, M.; Qu, M.; Tokuda, M. Experimental Observation and Image Analysis for Evaluation of Swelling and Fluidity of Single Coal Particles Heated with $\mathrm{CO}_{2}$ Laser. Energy Fuels 1997, 11, 730-738. [CrossRef]

45. Yu, D.; Xu, M.; Yu, Y.; Liu, X. Swelling Behavior of a Chinese Bituminous Coal at Different Pyrolysis Temperatures. Energy Fuels 2005, 19, 2488-2494. [CrossRef]

(C) 2019 by the authors. Licensee MDPI, Basel, Switzerland. This article is an open access article distributed under the terms and conditions of the Creative Commons Attribution (CC BY) license (http://creativecommons.org/licenses/by/4.0/). 